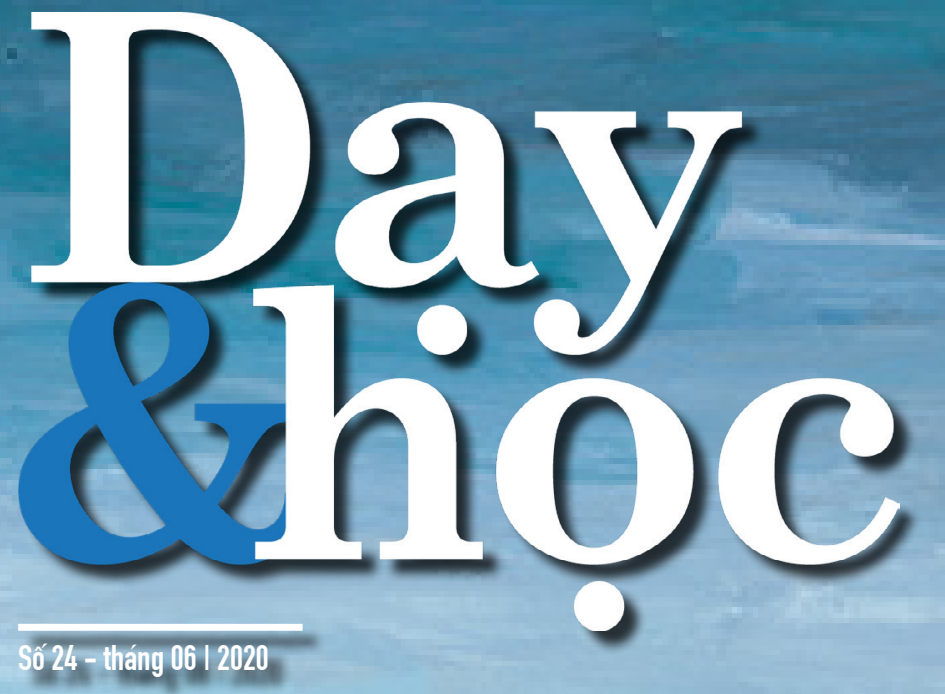

\title{
THICH ỨNG
}

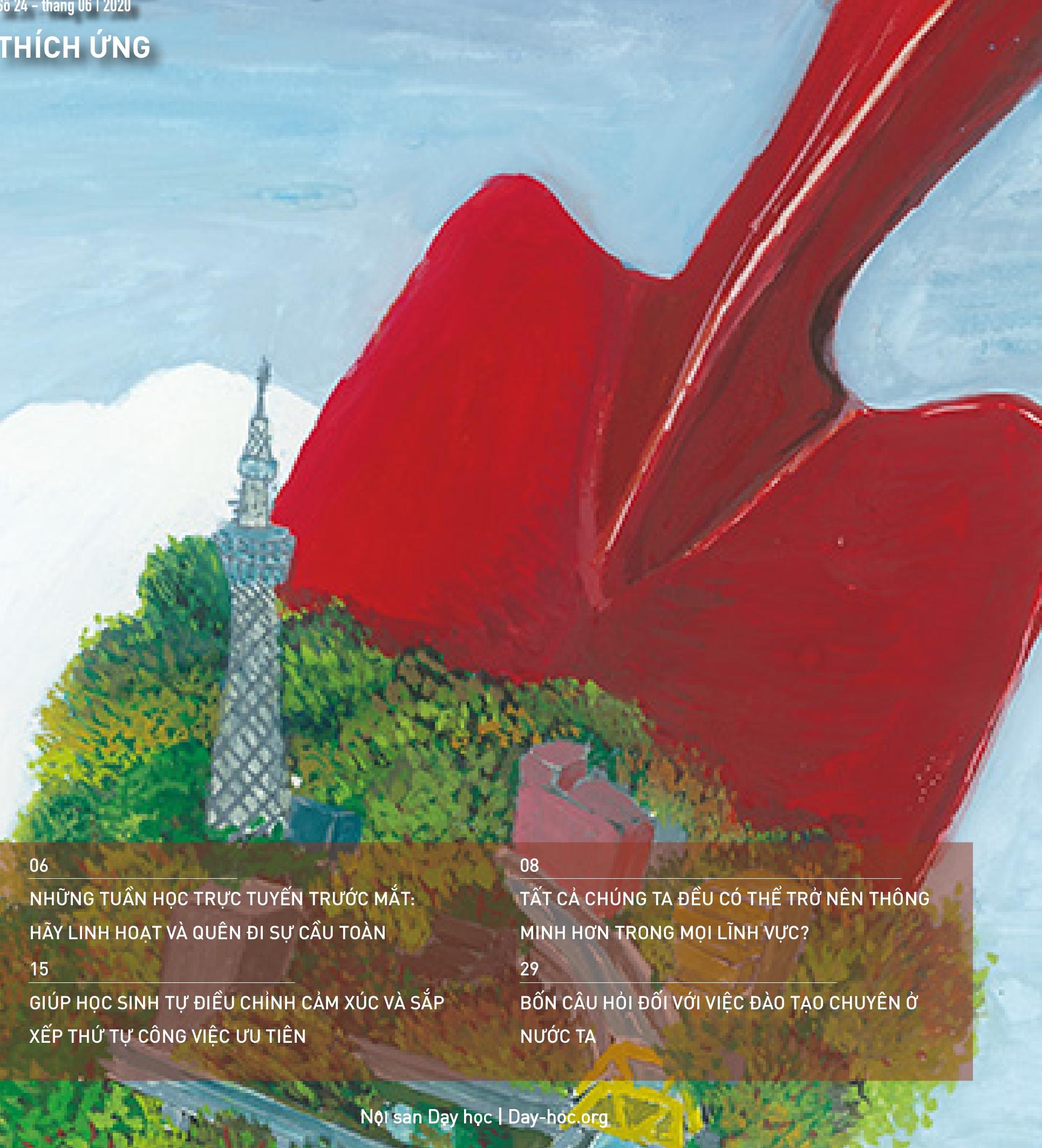



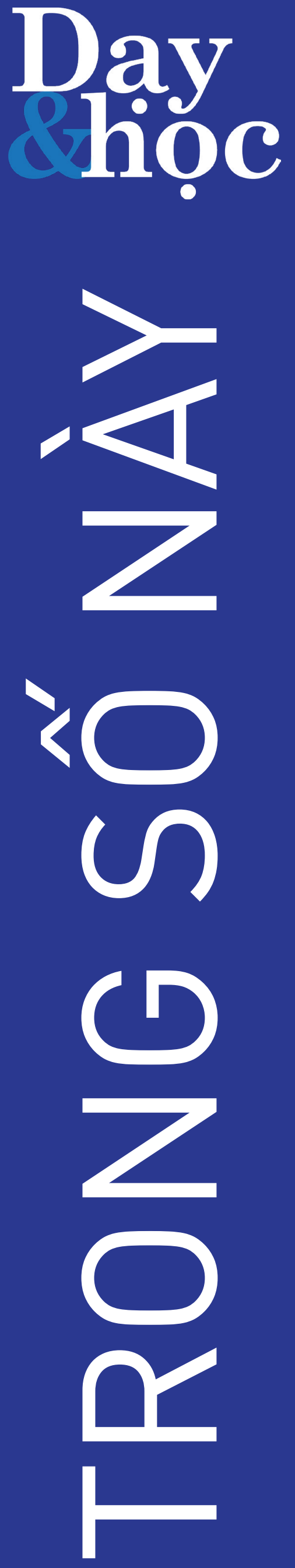

\section{Số 24: Thích ứng}

\section{Học thế nào?}

NHŨNNG TUÂNN HOC TRƯ⿱C TUYẾN TRƯỚC MẮT: HÃY LINH HOAT VÀ QUÊN ĐI SỰ CÂUU TOÀN .06

Nhật Hoa lược dịch

TẤT CẢ CHÚNG TA ĐỀU CÓ THỂ TRỞ NÊN THÔNG MINH HON TRONG MOI LINNH VỨC? .08 Hằng Lê Thanh dịch

\section{Dạy thế nào?}

CÁCH THỨC THỨC TẾ GIÚP HOC SINH TƯ ĐIÊU CHINH CẢM XÚC VÀ SẮP XẾP THỨ TỰ CÔNG VIẸC UUU TIÊN.......12 Nguyễn Ngọc Diệp dịch

NGHẸ THUÂT CỦA “CÁl NHIN CHẬM"

TRONG LỚP HOC 14

Phương Thuc dịch

BỐN CHIẾN LƯỢC KÍCH THÍCH ĐỘNG LỰC NỘI TAI CỦA HOC SINH 16 Nhật Hoa dịch

4 GIAI ĐOẠN PHÁT TRIỂN NHÂAN THỨC NỀN TẢNG VÀ CÁC KHÁl NIÊMM CHÍNH TRONG LÝ THUYẾT CUAA PIAGET 20 POMONA dich 


\section{Cải tổ giáo dục}

[30+ FRAMEWORKS GIÁO DUC] - KYे 7 -

KHUNG GIÁ TRI PHÁT TRIỂN DA - DEVELOPMENTAL ASSETS

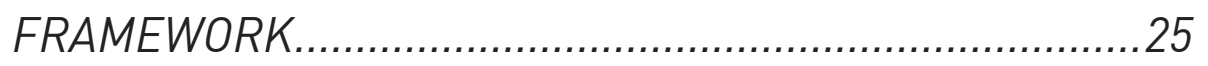

Đức Hoàng

XOÁ BỎ RÀO CÁN TRONG LỚP HOC

.26

Hoàng Giang Quỳnh Anh dịch

BỐN CÂU HỎI ĐỐI VỚI VIẸC ĐÀO TAOO CHUYÊN

ỚNUỚC TA

Phạm Hiệp

MINH BACH HÓA QUÁ TRINNH THU HÔI CÁC ẤN PHẨM HỌC THUÂT 32

Dương Phú Việt Anh tổng hợp

\section{Từ thực địa}

SỔ TAY NÂNG CAO SỨC KHOË TINH THẦN TRONG MÜA DICH 


\section{Thể lệ gửi bài:}

Quý thầy cô, anh chị có nội dung liên quan tới Dạy và Học muốn chia sẻ tới cộng đồng, xin vui lòng gửi về Ban Biên tập Lộn xộn qua email bientap@day-hoc.org

Cuối bài viết, tác giả xin vui lòng giới thiệu vài nét về bản thân: Họ tên, nơi công tác, địa chỉ liên lạc, số điện thoại, các chủ đề nghiên cứu yêu thích...

Do thời gian và nhân sụ̣ có hạn, Ban Biên tập xin phép chỉ liên hệ với các bài viết được chọn đăng.

\section{Tinh thần 4.0}

Ban Biên tập và quý thầy cô, anh chị gửi bài cộng tác đều chia sẻ tinh thần 4.0, tức là:

- 0 lương

- 0 văn phòng

- O chuyên môn cao

- 0 gióri hạn không gian - thời gian

\section{Địa chỉ gửi bài:}

Bientap@day-hoc.org

\section{Chia sè:}

Quý thầy cô, anh chị cảm thấy nội dung Dạy và Học có ích, xin vui lòng chia sẻ tới bất kỳ những ai quan tâm, kèm theo trích dẫn nguyên vẹn và đầy đủ về nguồn gốc bài viết.

\section{Mọi người nói về Dạy \& Học}

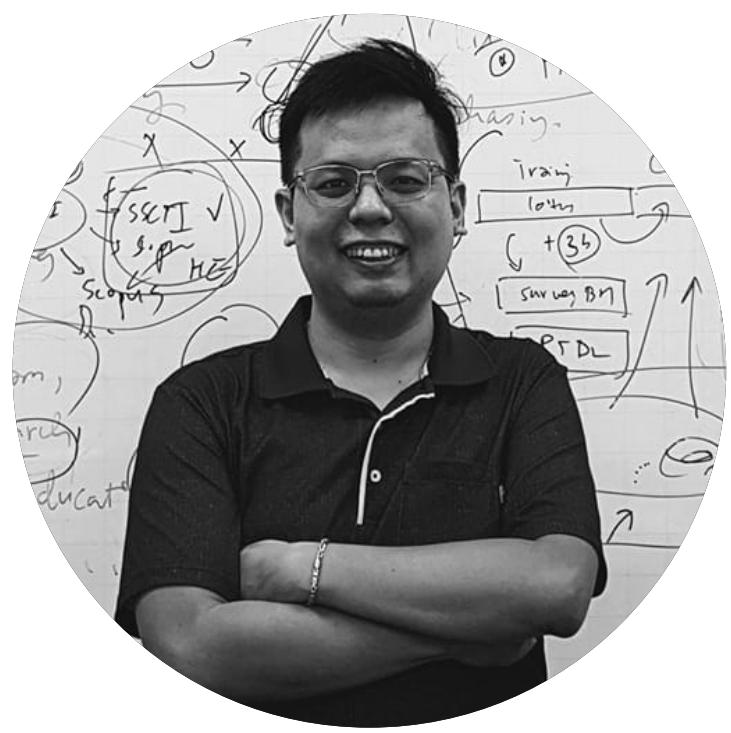

"Dạy \& Học là ấn phẩm không thể thiếu đối với các nhà trường phổ thông"

- TS Phạm Hiệp, Chuyên gia Giáo dục 


\section{Lời tựa}

Quý độc giả thân mến,

Dịch COVID-19 vẫn đang ảnh hưởng sâu, rộng đến thực trạng học và dạy ở nhiều nơi trên thế giới. Chúng ta đã dần thân thuộc hơn với thuật ngữ “bình thường mới”, nhưng cũng khó lòng mà có được mô tả chân thực về những "bình thường mới” ấy. Dạy\&Học số 24 với chủ đề 'Thích ứng' xin góp đôi chút suy tư cùng quý vị về những điều "bình thường mới".

“Những tuần học trực tuyến trước mắt: hãy linh hoạt và quên đi sự cầu toàn” - đây là lời nhắn nhủ yếu cho các quốc gia đang phải tạm đóng cửa hệ thống trường học, nhất là đối với những quốc gia đang bỡ ngỡ với các chuyển đổi số trong giáo dục. Việc xây dựng quan điểm phù hợp của nhà trường và phụ huynh đối với việc học tập trong giai đoạn này, sẽ là sự hỗ trợ có ý nghĩa thiết thực với học sinh. Bên cạnh đó, quý vị có thể tham khảo "Cách thức thực tế giúp học sinh tự điều chỉnh cảm xúc và sắp xếp thứ tự công việc ưu tiên" và "Bốn chiến lược kích thích động lực nội tại của học sinh".

Bên canhh những suy tư về giáo dục trong mùa dịch, hãy cùng chuẩn bị cho những sự cải tổ mà bất cứ ai cũng đều có thể đem lại.

Trong tuần qua, các thảo luận trên mạng xã hội và một số báo điện tử xoay quanh câu chuyện trường chuyên lớp chọn đã thu hút nhiều sự chú ý. Vậy, bất kể trong trạng thái "bình thường" hay "bình thường mới", liệu "Tất cả chúng ta đều có thể trở nên thông minh hơn trong mọi lĩnh vực?”. Dạ\&Học số 24 xin mời quý vị cùng tham khảo “4 giai đoạn phát triển nhận thức - Nền tảng và các khái niệm chính trong lý thuyết của Piaget”, và cùng suy ngẫm vể “Bốn câu hỏi đối với việc đào tạo chuyên ở nước ta”.

\section{Ban Biên tập Lộn Xộn}


TẤT CẢ CHÚNG

TA DỀU CÓ

THỂ TRỞ NÊN

THÔNG MINH

HON TRONG

MỌI LĨNH VựC?

Tina Barseghian | Lê Thanh Hằng dịch
Khi một học sinh nhận được điểm tốt, chiến thắng một giải thưởng hoặc vẽ được một bức tranh đẹp, chúng ta đều biết rằng thời điểm đó, chúng ta không nên nói "Rất tốt!". Ca ngợi thành tích chứ không phải nỗ lực sẽ gây phản tác dụng.

Đối với trẻ em, "Rất tốt" có nghĩa là "Con rất thông minh" hay "Con rất tài năng" - đó là những lời khen ngợi dành cho khả năng vốn có, khả năng bẩm sinh hoặc trí thông minh của trè. Nhưng niềm kiêu hãnh lóe lên chớp nhoáng sẽ nhanh chóng chìm sâu vào nỗi nghi ngờ khi trẻ trải qua một thách thức nào đó lớn hơn và không thành công ngay lập tức.

Những trẻ được ca ngợi là thông minh thường quan tâm về điểm số, danh hiệu và giải thưởng hơn so với những trẻ được ngợi ca vì nỗ lực, theo báo cáo nổi tiếng của Stanford năm 1998 "Ảnh hưởng của trí thông minh và ảnh hưởng của lời khen ngợi" bởi Claudia Mueller và Carol Dweck. Nghiên cứu chỉ ra rằng "sau khi thất bại, [trẻ] cũng có biểu hiện ít kiên trì trong công việc, ít thích thú với công việc và thực hiện nhiệm vụ tệ hơn so với trẻ được khen ngợi do nỗ lực."

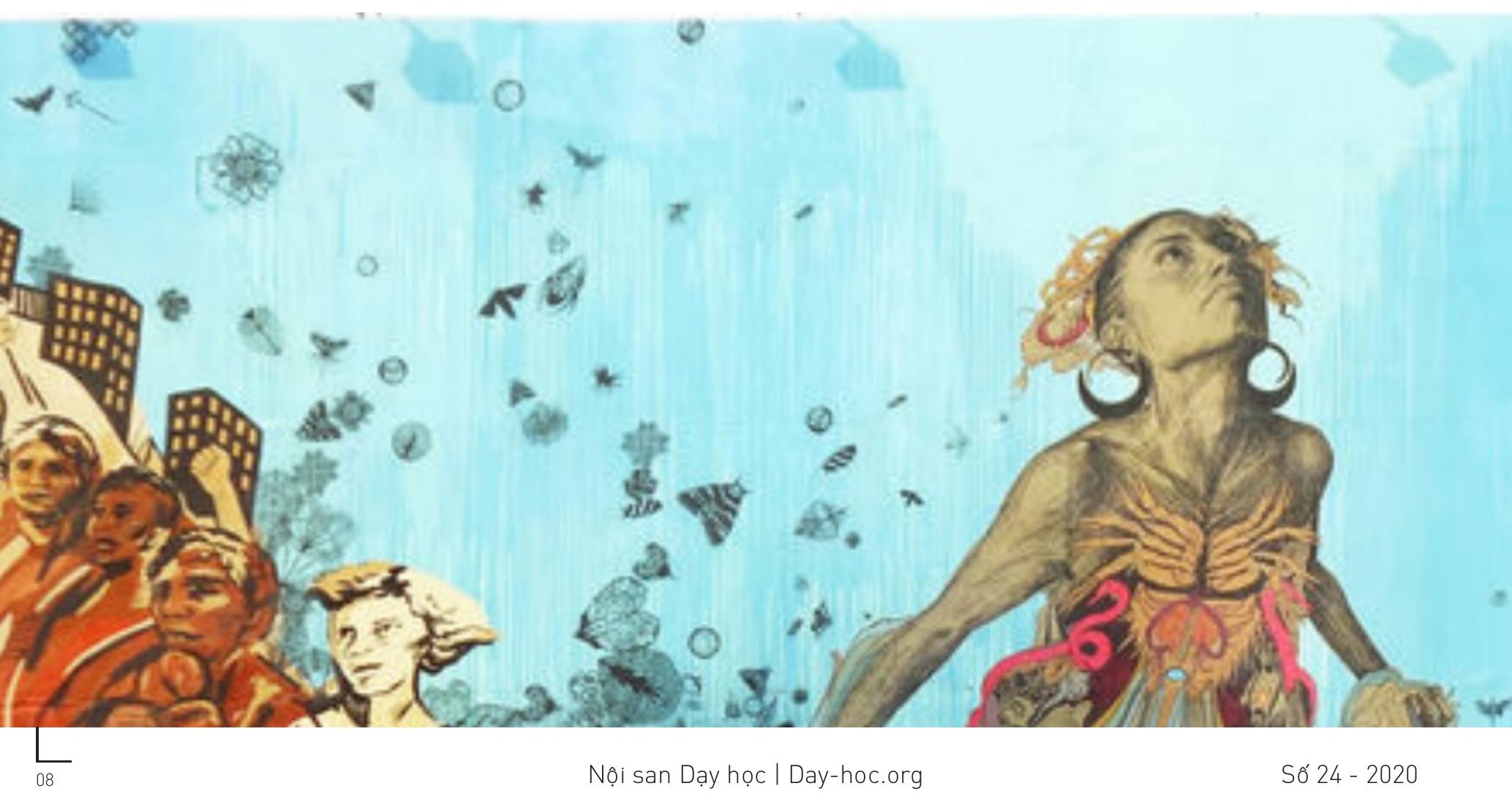




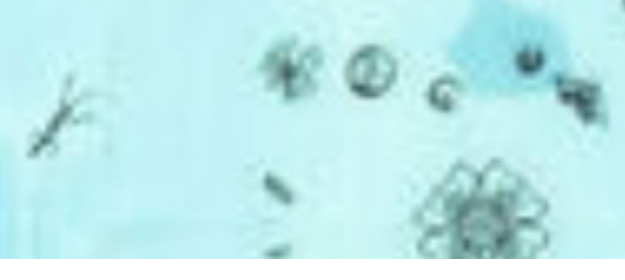

Nhưng cũng có một tác dụng phụ khác: trẻ được ca ngợi là thông minh "sẽ coi đó là một đặc điểm cố định hơn trẻ được ca ngợi chăm chỉ, và những trẻ này cũng tin rằng chăm chì là cần phải cái tiến."

Tại sao điều đó không tốt? Bởi vì nói với trẻ rằng trẻ thông minh khi nhận được điểm tốt sẽ khuyến khích trẻ tiếp tục tập trung vào điểm số hơn là quá trình học tập. Những trẻ này luôn muốn giữ sự thông minh cho minh

\section{Đằng sau trí thông minh}

Trong nhiều năm gần đây, nghiên cứu về cách thức học tập của não bộ được xây dựng trên những nghiên cứu đó. Trên phụ san Ideas lý tưởngl của tạp chí Time, tác giả Annie Murphy Paul ${ }^{1}$ đặt vấn đề về Learning curve (đường cong học tập): "Làm thế nào chúng ta biết được hình dáng của những gì chúng ta biết và những gì chúng ta có thể làm được?". "Những kiến thức và khả năng của chúng ta chủ yếu được xác định không chỉ bởi chỉ số IQ hay các thước đo trí thông minh cố định khác, mà còn ở hiệu quả của quá

$1 \quad$ http://ideas.time.com/2011/10/12/the-science-of-how-we-learn/\#ixzz1cl1QGIPI trình học tập của chúng ta: ta gọi nó là thương số học tập (learning quotient)."

Quan điểm cho rằng ai cũng có thể học, bất kể chỉ số $I Q$ vốn có của họ - với sự nhấn mạnh về quá trình, công việc, nỗ lực - được cổ suý bới Rodolfo Mendoza-Denton², giáo sư tâm lý học tại Đại học Berkeley.

Mendoza-Denton mở rộng ý tưởng về những tác hại khi nhấn mạnh vào thành tích và trí thông minh cũng có thể gây hại tới phong cách học tập (âm thanh, hình ảnh) hoặc "đa trí tuệ", một lý thuyết của giáo sư Howard Gardner, đại học Harvard, phân biệt các loại trí thông mình của người học người học: không gian, ngôn ngữ, logic toán học..v.v.

Mendoza-Denton tin rằng nhấn mạnh vào "trí thông minh tự nhiên" sẽ củng cố thêm niềm tin rằng trẻ em tốt ở một số mặt, ngược lại, kém ở một số mặt. "Điều này là phổ biến trong câu chuyện văn hóa," Mendoza-Denton cho biết: “'Tôi không phải là loại người học này hay loại người học kia. Tôi rất giỏi ngôn ngữ, nhưng không phải toán học."

\section{2 http://blogs.berkeley.edu/author/rmendoza-den-}

ton/

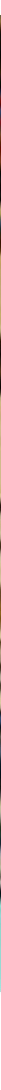


Xa hơn, trẻ em có thể nghĩ rằng nếu họ phải chăm chỉ làm một việc gì đó, cũng có nghĩa là họ không thông minh. "Đó là một lý thuyết về cách thế giới hoạt động," ông nói.

Một đề tài trên NPR ${ }^{3}$ hỗ trợ cho lý thuyết của Mendoza-Denton. Mặc dù “đã có toàn bộ một ngành công nghiệp xây dựng dựa trên phong cách học tập, thì cũng có" một nghiên cứu xem xét lại phong cách học tập đã khiến nhà tâm lý học Doug Rohrer tin rằng "không có bằng chứng khoa học cho quan điểm này."

“Chúng tôi đã không tìm thấy bằng chứng nào từ một thí nghiệm đối chứng ngẫu nhiên, và cho đến khi bằng chứng như vậy tôn tại, chúng tôi không thể đề xuất rằng quan điểm ấy nên sử dụng", ông nói với NPR.

Nhà nghiên cứu khác đưa ra thêm quan điểm nhiều khía cạnh hơn. Trong một câu chuyện của California Watch ${ }^{4}$, một nhà nghiên cứu đặt câu hỏi về tác động của việc gọi ra khả năng tự nhiên. “Rõ ràng, con người có cả khả năng đặc biệt lẫn năng khiếu. Một số người có khả năng thị giác tốt hơn, và một số có khả năng thính giác tốt hơn “, giáo sư Hal Pashler của UCSD, tác giả chính của báo cáo cho biết. "Nhưng câu hói là liệu có thể dự đoán bất cứ điều gì về cách thức hiệu quả nhất để dạy cho họ. ... Hoàn toàn thiếu bằng chứng cho những luận điểm này."

Điều này đã gây ra một cuộc tranh luận lớn trong giới giáo dục bởi những người đặt câu hỏi về động lực của những phong cách học tập đó. Nhưng Mendoza-Denton cho rằng việc coi quan điểm nhấn mạnh sự nỗ lực của tré quan trọng tương đương, thậm chí hơn trí thông minh bẩm sinh sẽ đặt học sinh vào con đường học tập tốt nhất.

Và điều quan trọng không kém, đó là sai lầm cũng là một phần của việc học tập tốt. Như một bài báo Wired ${ }^{5}$, báo cáo về lý do tại sao học tập

3 http://www.npr.org/blogs/

health/2011/08/29/139973743/think-youre-an-audito-

ry-or-visual-learner-scientists-say-its-unlikely

4 http://californiawatch.org/dailyreport/research-

ers-question-learning-styles-theory-12734

5 http://www.wired.com/wiredscience/2011/10/whydo-some-people-learn-faster-2/ từ những sai lầm lại hiệu quả hơn, “quan trọng là những gì sẽ xảy ra tiếp theo." Những người có "hệ tư duy phát triển (growth mindset)" - những người “tin rằng chúng ta có thể làm tốt hơn hầu như bất cứ điều gì, miễn là chúng ta đầu tư thời gian và năng lượng cần thiết “- là sẽ học được tốt hơn từ những sai lầm của họ.

Dĩ nhiên, điều này cũng đề cập đến vấn đề công bằng xã hội, mang lại niềm tin khuôn mẫu về giới tính và chủng tộc - người châu Á giỏi toán hơn, cô gái này là kém hơn môn toán, người Mỹ gốc Phi không làm tốt các bài kiểm tra như SAT. Mendoza-Denton trích dẫn một số nghiên cứu cho thấy sinh viên làm việc xứng đáng (hoặc không) với những kỳ vọng đặt ra cho họ. Đó là do cách họ tự thực hiện.

Tất cả những điều này không phải để nói rằng con người không có tài năng đặc biệt. "Mọi người có những năng khiếu, đó là khổng thể phủ nhận," ông nói. "Có thể tất cả chúng ta không phải là thiên tài, nhưng chúng ta có tất cả mọi thứ để tiếp cận việc học tập."

Vì vậy, những điều cha mẹ và giáo viên nên biết từ đây là gì? Đó là những gì chúng ta có thể xem xét để hô̂ trợ việc học tập - ví dụ như tạo kết nối với các giáo viên hoặc cố vấn, những lời khen ngợi về làm việc chăm chỉ hơn điểm tốt - là thực sự quan trọng đối với thành tích học tập của trè. “Những điều đơn giản có thể ảnh hường đến thành tích một cách sâu sắc". 


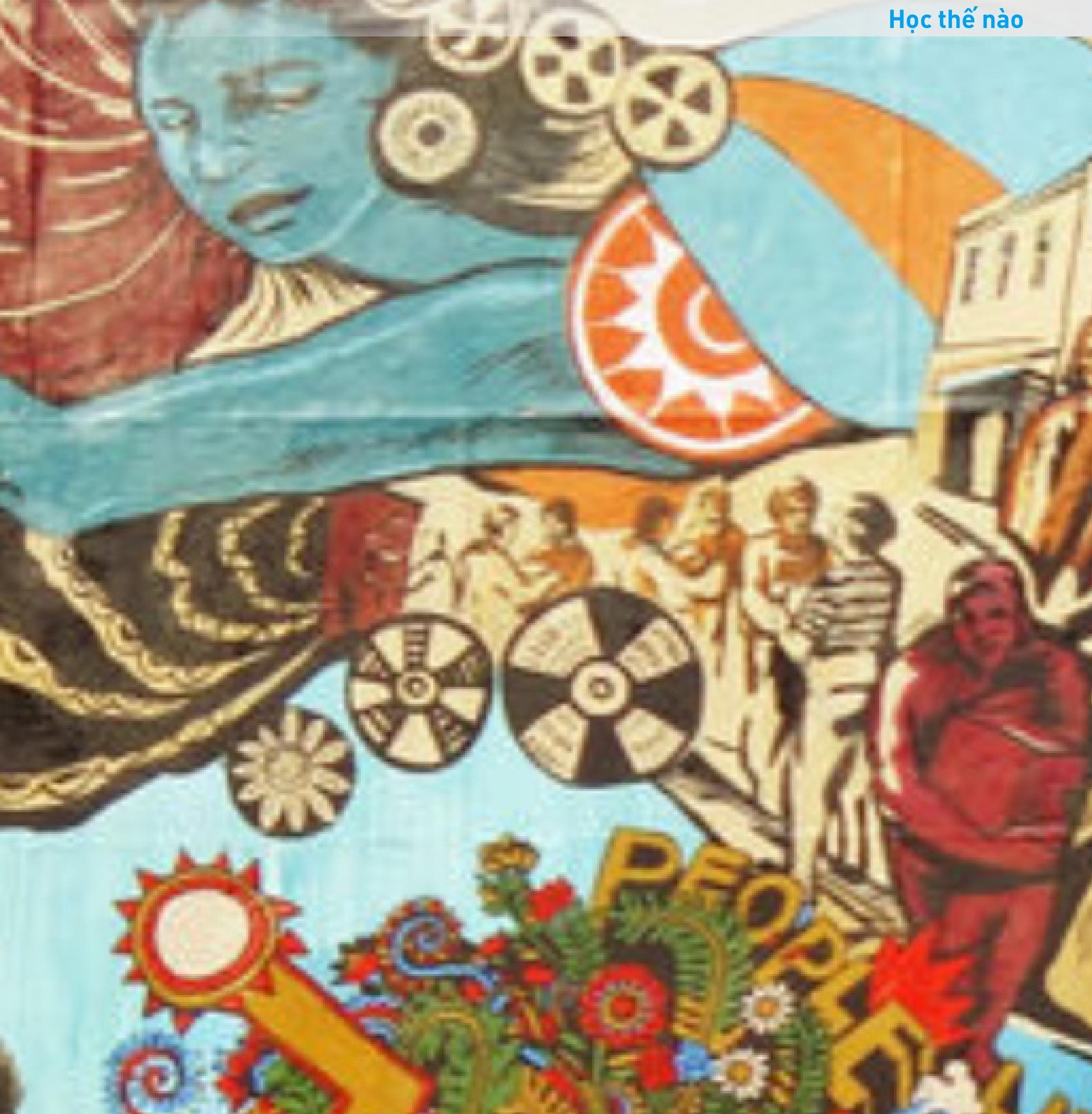

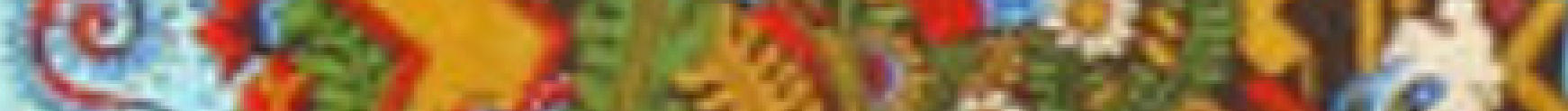

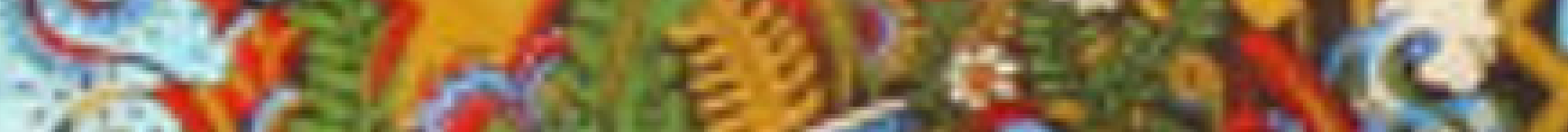

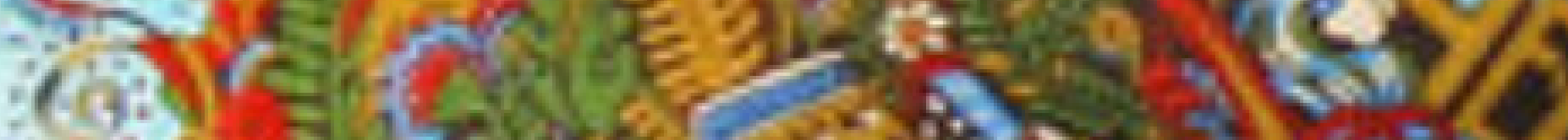

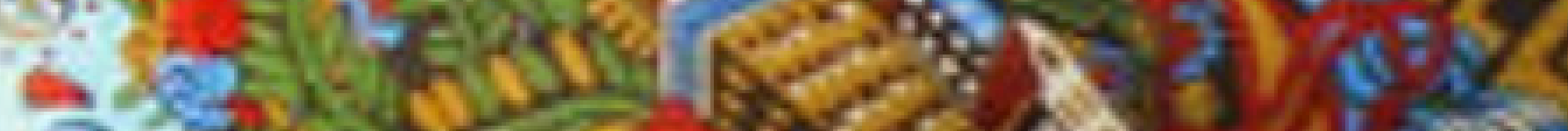

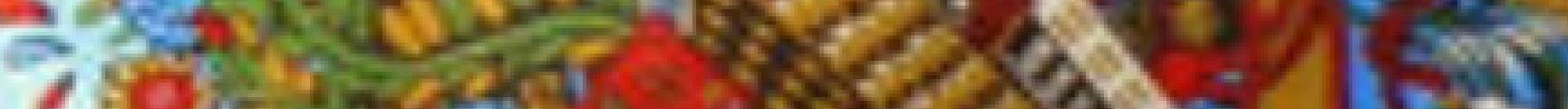

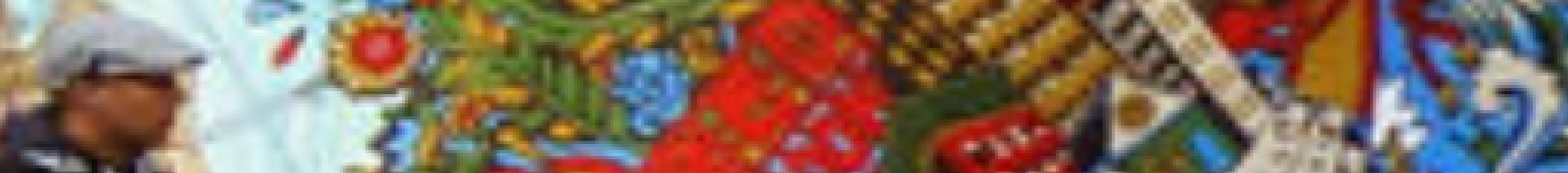

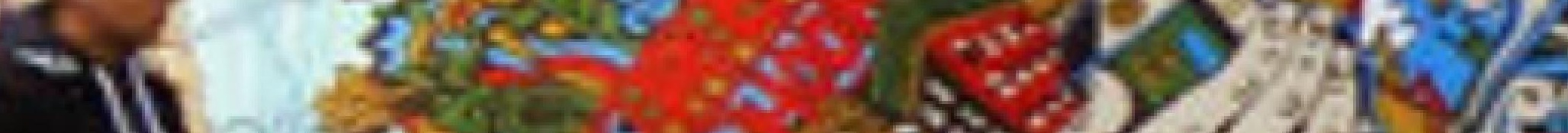




\section{Cớch thức thực tế giúp hoc sinh tư ciều chinh cảm xúc và̀ sắp xếp thứ tự công việc ư tiên'}

Katrina Schwartz | Nguyễn Ngọc Diệp dịch²

Có rất nhiêuu kỹ năng cẩn thiết để môt học sinh có thể thành công trong trường học ngoài việc hiểu nội dung bài học thật kỹ. Những kỹ năng này gổm có khả năng nhận biết, đặt tên và kiểm soát cám xúc cưa minh. Ngày đến trường với học sinh thường đi kèm với rất nhiêuu cám xúc, tất cả mọi cung bậc từ phấn chấn cực độ đến thất vọng tột độ, và trường học chính là một môi trường tốt để mỗi học sinh thực hành tự điều chỉnh cảm xúc.
“Một trong những cách xác thực nhất để tôi giúp học sinh của tôi mở rộng vốn từ vựng của bản thân là dùng trải nghiệm cá nhân mình để thể hiện cảm xúc của chính tôi trong lớp học", Lindsey Minder, một giáo viên lớp hai cho hay. Cô thường xuyên diễn đạt, mô tả cảm giác của cô ấy và giải thích cho học sinh tại sao trong những ngày lên lớp, cũng như làm các cách thực hành đơn giản như hít một hơi thật sâu để bình tĩnh cho học sinh xem.

\footnotetext{
1 Tựa gốc: Concrete Ways To Help Students Self-Regulate And Prioritize Work Link: https://www.kqed.org/mindshift/53132/ concrete-ways-to-help-students-self-regulate-and-prioritize-work
}

${ }^{2}$ Katrina Schwartz là một nhà báo có làm việc tại San Francisco. Cô ây làm việc tại đài phát thanh công cộng KPCC ở LA và là phát thanh viên trực tuyến cho KQED từ năm 2010. Cô phụ trách mảng cách dạy và học thay đổi cho MindShift từ năm 2012 đến 2020. Cô là người đông chủ trì podcast MindShift và hiện làm Podcast KQED's Bay Curious. 


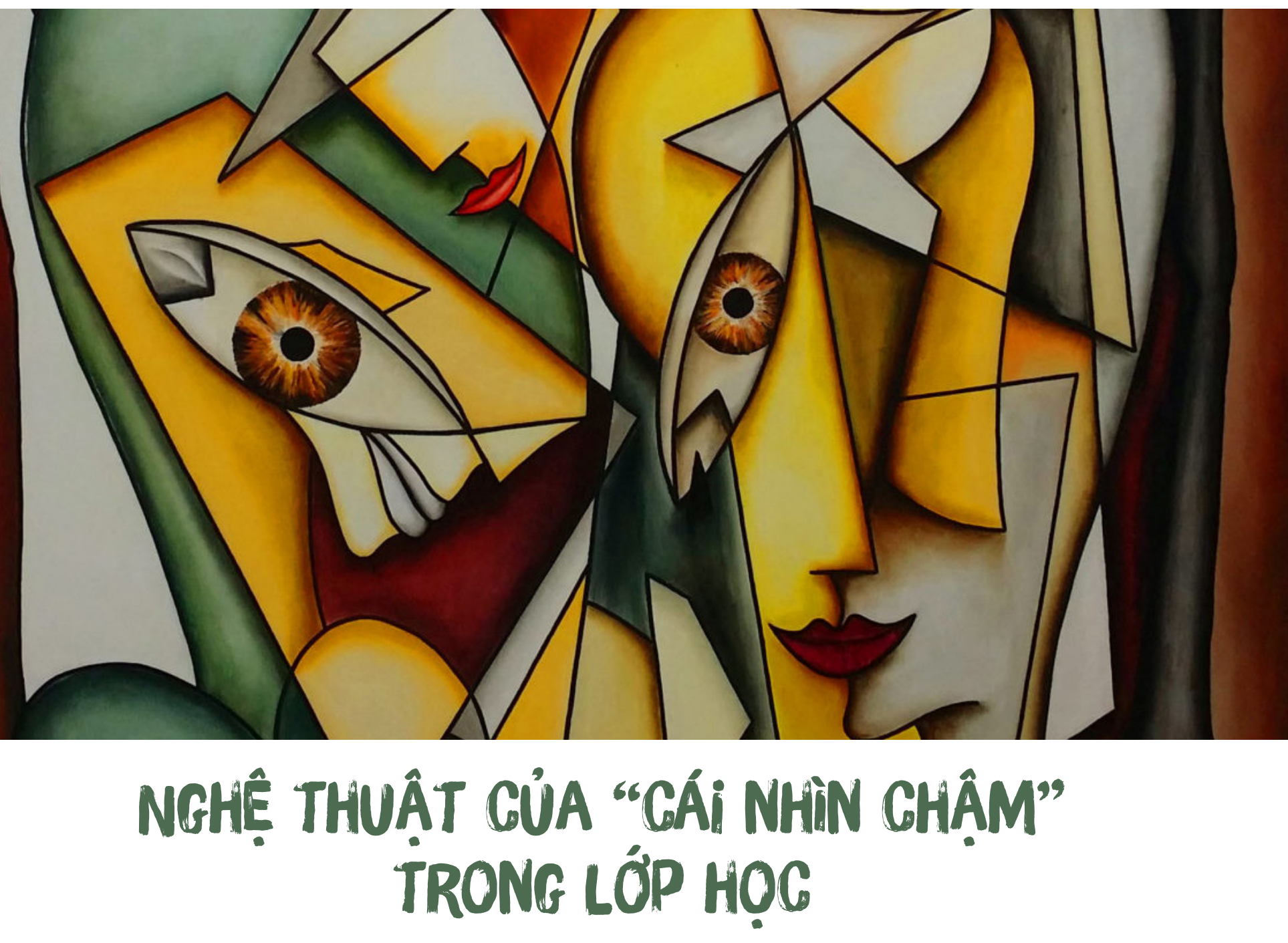

Emily Boudreau ${ }^{1}$ | Phương Thục dịch

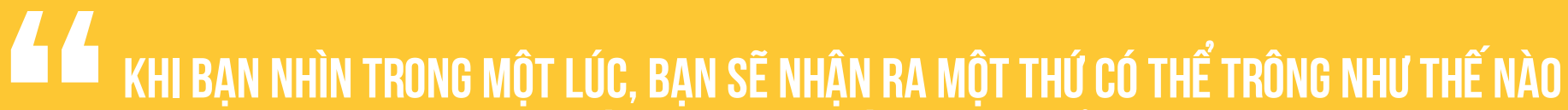

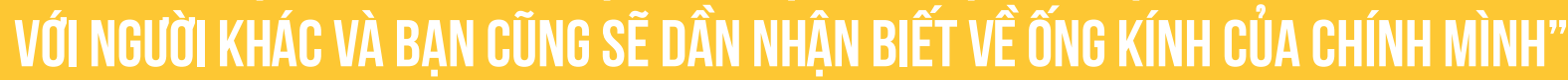

- Shari Tishman, nhà nghiên cứu của Project Zero

Tám giây - đó là ước tính mới nhất về độ dài khoảng chú ý của con người. Việc thúc đẩy sử dụng nhiều chất liệu giảng dạy hơn trong cùng một khoảng thời gian tiết học cũng mang đến một thách thức, đặc biệt là khi giáo viên được thông báo rằng các kỹ năng, Inhư tư duy phản biện và sáng tạo) mà học sinh của họ sẽ cần để cạnh tranh trong thế kỷ 21, là những điều cần có thời gian để phát triển. Đối với các nhà giáo dục làm việc với một thế hệ mới, lớn lên trong một thế giới mà sự trao đổi thông tin diễn ra nhanh chóng, việc giữ được sự chú ý của sinh viên trong những lúc đòi hỏi sự quan sát trở nên khó khăn.

Như một liều thuốc giải cho vấn đề trên, Shari Tishman, đề xuất "cái nhìn chậm” Islow lookingl, là phương pháp thực hành quan sát chi tiết theo thời gian để vượt qua ấn tượng đâu tiên và tạo ra trải nghiệm đắm chìm với một văn bản, một ý tưởng, một tác phẩm nghệ thuật hoặc bất kỳ hình thức nào khác. Việc thực hành này tạo ra một không gian để học viên nắm giữ và trân trọng sự phong phú của thế giới mà chúng ta đang sống.

1 Tựa gốc: The Art of Slow Looking in the Classroom, link: https://www.gse.harvard.edu/news/uk/20/01/art-slowlooking-classroom 


\section{LÀM THẾ NÀO “CÁl NHìn CHẬM” CÓ THỂ HỖ TRỌ SINH VIÊN}

Cái nhìn chậm giúp học sinh điều hướng các hệ thống phức tạp và xây dựng các kết nối

Hoạt động: Phân tách một cái gì đó ra, cho dù đó là một đồ vật vật lý hay một khái niệm như "gia đình". Các thành phần khác nhau là gì và làm thế nào để chúng hoạt động cùng nhau?

Tishman nói rằng: “Nhìn vào các vật thể vật lý hoặc khái niệm, cách chúng kết hợp với nhau và cách chúng có thể tách rời nhau là một chiến lược tốt cho "cái nhìn chậm". Tishman đã cho các sinh viên tốt nghiệp của minh tách các đồ vật hàng ngày thành các nhóm nhỏ, suy nghĩ về vai trò của các bộ phân khác nhau và tạo ra một kho lưu trữ các mảnh mà họ tìm thấy. Trong hoạt động này, sinh viên phát triển nhận thức về sự phức tạp và cách thức các mảnh nhỏ có thể kết hợp với nhau để tạo thành một tổng thể lớn hơn, theo đó, truyển cảm hứng cho học sinh sử dụng những gì họ biết để thiết kế hệ thống mới.

\section{CÁl NHìn CHẬM TIẾP NHIÊN LIÊUU CHO SỤ ĐỒNG CẢM VÀ TƯ NHÂN THỨC}

Hoạt động: Thay đổi điểm thuận lợi của bạn. Điều đó có thể là nhìn bằng mắt thường và sau đó nhìn qua kính hiển vi, cũng có thể là yêu cầu học sinh tưởng tượng về một ly nước sẽ trông như thế nào đối với một con kiến hoặc nghiên cứu các dụng cụ ăn uống từ khắp nơi trên thế giới.

“Khi bạn nhìn trong một lúc, bạn sẽ nhận ra một thứ có thể trông như thế nào với người khác và bạn cũng sẽ dần nhận biết về ống kính của chính mình" Tishman nói. Thông qua việc nhìn chậm, học sinh sẽ hiểu được bản chất đa quan điểm của việc hiểu biết về mọi thứ trong thế giới của chúng ta. Nhìn chậm cho phép sinh viên hiểu cách họ nhìn thấy một cái gì đó qua lăng kính của chính họ - và mở ra cho họ những cách nhìn nhận khác nhau về cùng một đối tượng hoặc ý tưởng của những người khác trong lớp học và trên thế giới. Nó cũng cung cấp một không gian để họ chú ý đến sự tương đồng trong các quan điểm khác nhau.

\section{HỌC SINH CÓ THỂ CÙNG NHAU TU DUY VÀ XÂY DỰG Ý TUỞNG Mớl.}

Hoạt động: Cho cả lớp nhìn vào một đối tượng hoặc hình ảnh. Đi xung quanh và yêu cầu mối học sinh nói một điều họ chú ý về đối tượng đó. Họ không thể lặp lại, nhưng họ có thể bổ sung thêm vào những gì mà một bạn cùng lớp đã nêu. Suy ngẫm về những gì học sinh đã chọn: Điêuu gì giống hay khác nhau? Họ có câu hỏi gì?

Nhiều trong số những trải nghiệm nhìn chậm thực sự rất mạnh mẽ khi được thực hiện theo nhóm vì nó dựa trên sự phấn khích được tạo ra khi đến lượt bạn hoặc khi bạn nghe những gì người khác nói, ông Tishman nói. Thông thường, một thành viên trong nhóm sẽ chia sẻ một cái gì đó giúp khơi dậy suy nghĩ mới hoặc đề cập đến một cái điều gì đó mà những người khác có thể không nhận thấy được lúc ban đầu.

\section{HỌC SINH HỌC ĐUỰC CÁCH MÔ TẢ CHI TIÊT}

Hoạt động: Mô tả không bắt buộc phải là viết ra. Cho học sinh của bạn vẽ một cái gì đó nhiêuu lần. Họ đã chú ý đến điều gi ở lần đầu tiên? Có thứ gì họ nhìn nhận thêm được ở lần thứ hai không? Họ đã chú ý thêm điều gì khi họ tiếp tục nghiên cứu về đối tượng?

Đôi khi, cái nhìn chậm có thể hình thành thói quen tìm kiếm ngày càng nhiều điều cần chú ý, ông Tishman nói. Bạn có thể nhìn nhận những thứ xuất hiện theo thời gian. Hãy chú ý những gì gây ấn tượng với bạn như thể đó là điều hiển nhiên, những ấn tượng đầu tiên của bạn, những gì đang ẩn giấu và những gì bạn có thể khám phá. Mặc dù giáo viên hướng dần thường có thể yêu học sinh viết ra những quan sát này, những bản vẽ cũng có thể cung cấp những loại hiểu biết có ý nghĩa tương tự. Đặc biệt nếu bạn nhấn mạnh rằng điểm chính của hoạt động không phải là một bức tranh chính xác, mà là việc chú ý đến các chi tiết nhiều hơn. Bạn cũng có thể yêu cầu học sinh chuyển các bản vẽ của họ thành một đoạn viết có mức độ chi tiết tương tự như bản vẽ. 


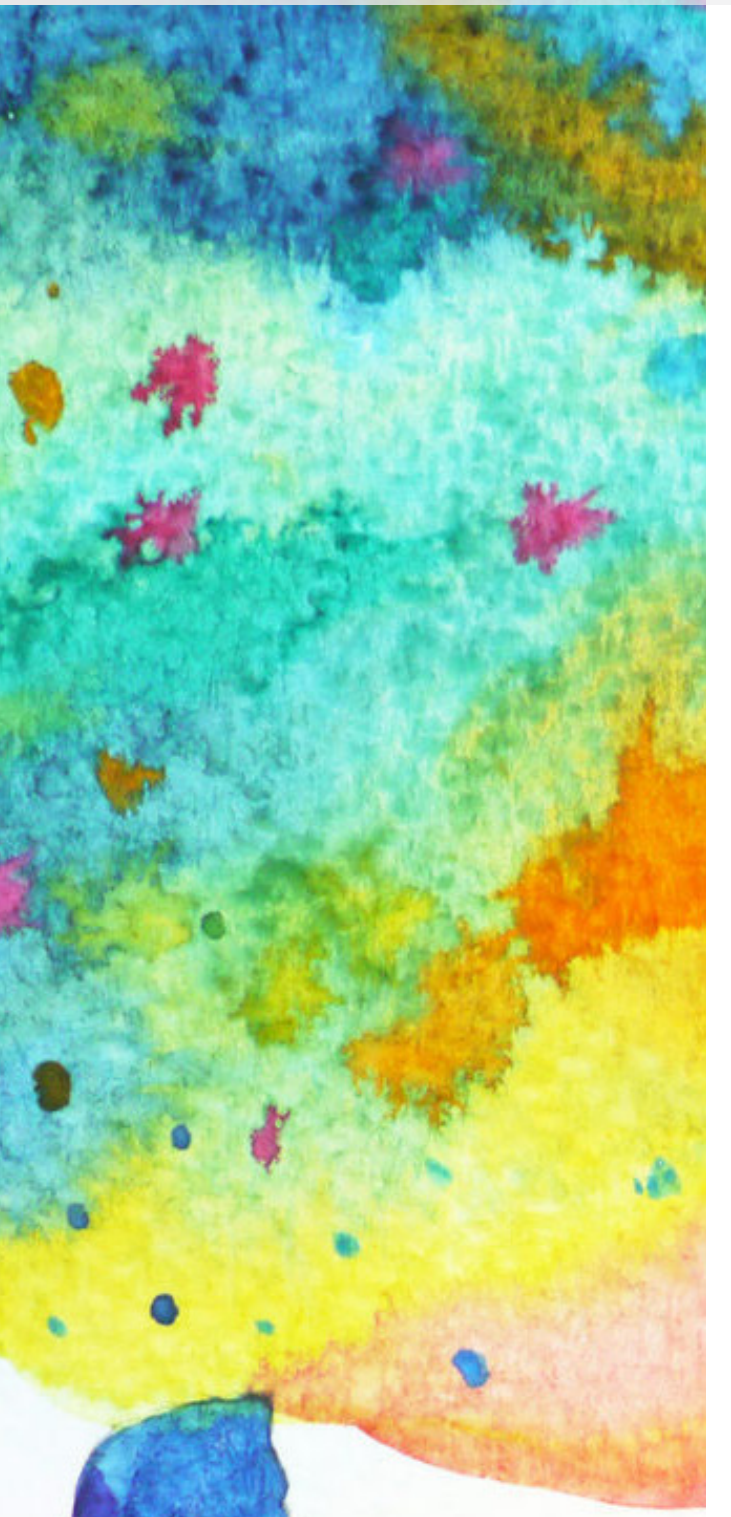

Aông liec nồ Lavi ciea hoc sinh dịch

Kathy Digsby đã dạy ở trường tiểu học trong một thời gian dài. Trước đó, cô đã từng dạy ở trường mẫu giáo nhiều năm trước khi chuyển lên lớp một. Mặc dù đã gần sáu mươi và chuẩn bị nghỉ hưu, một phần trong bà không muốn rời bỏ lớp học. Gần đây, bà đã khuấy động việc học bằng cách đưa việc được lựa chọn vào càng nhiều mảng trong lớp học để có thể gắn kết những học sinh nhỏ tuổi của minh. Và việc đó thật sự thú vị.

'Tôi nghĩ rằng, là giáo viên, chúng ta luôn cảm thấy minh cần kiểm soát tất cả mọi thứ để lũ trẻ cảm thấy ổn và để chúng có thể học' Digsby chia sẻ. Một ví dụ điển hình chính là từ những trạm '5 mỗi ngày' mà học sinh thay phiên thực hiện trong giờ Tiếng Anh Ngôn Ngữ Nghệ thuật. Ở một bàn, Digsby thường thực hiện đọc có hướng dẫn với một nhóm nhỏ. Cứ mỗi 20 phút, lũ trẻ lại được đổi trạm để hoặc tự đọc cho mình nghe, hoặc tập viết, làm bài tập từ hoặc luyện tập mỗi kĩ năng trên máy tính. Khi đồng hồ bấm giờ kêu, học sinh lại tự đổi dù chúng đã hoàn thành bài tập đó hay chưa.

\section{Tựa gốc: Four Re-} search-Based Strategies To Ignite Intrinsic Motivation In Students I KQED, link: https://www.kqed.org/ mindshift/53426/four-research-based-strategies-to-ignite-intrinsic-motivation-in-students
'Việc đó gây bực mình kể cả với tôi, tôi khó có thể tưởng tượng bọn trẻ còn cảm thấy thế nào nữa' Digsby nói.

Vì thế, cô quyết định đưa việc lựa chọn vào hệ thống chuyển trạm. Thay vì đưa ra những những nhóm đọc đưa chia theo trình độ khiến gây ra sự quản lý vì những bạn đọc kém nhất sẽ bị nhóm với nhau. Cô để cho học sinh chọn trạm mình bắt đầu và tin tưởng chúng tự chọn khi nào chúng hoàn thành và muốn đổi trạm. Cô cũng để chúng chọn chúng muốn làm việc ở góc nào của lớp và với ai.

Cô biết rằng việc thêm yếu tố lựa chọn vào sẽ khiến nhiểu học sinh có câu hỏi và bị mắc kẹt, vì vậy cô trước tiên nói với cả lớp về ý nghĩa của việc * coach* người khác. Lớp sẽ cùng trò chuyện về việc không đưa câu trá lời ngay vì như vậy sẽ không giúp bạn mình học và tầm quan trọng của việc cùng làm việc tốt với nhau.

'Tôi chứng kiến một sự thay đổi lớn ở mức độ gắn kết, mức độ nói chuyện trong lớp và cả không khí chung của lớp khi chúng tôi chuyển sang lựa chọn,' Digsby nói.

Những ý tưởng về đưa thêm lựa chọn vào trong lớp học xuất phát từ một buổi thảo luận về phát triển chuyên môn do Zac Chase, giám đốc chương trình môn ngôn ngữ nghệ thuật. Digsby chuyển sang trường thuộc quận St. rain đặc biệt bởi cô cảm thấy 
sự phát triển chuyên môn ở đấy sẽ thúc đầy cô thành một giáo viên tốt hơn.

Chase cũng có những buổi thuyết trình tương tự về động lực với giám đốc điều hành của Inquiry Schools, Diana Laufenberg, tại hội nghị EduCon tổ chức bởi Học viện Lãnh Đạo Khoa học ờ Philadelphia. Họ thuyết trình về những nghiên cứu về cảm tính và động lực tình huống mà thực tế có thể thực hiện trong lớp học.

'Nghiên cứu cho thấy học sinh mà cảm thấy rằng bài tập ở trường thú vị và có ý nghĩa thì chúng sẽ gắn kết về mặt nhận thức trong việc cố gắng hiểu bài' Laufenberg nói với những nhà giáo có mặt. Điều đó cũng có nghĩa là học sinh cần có động lực từ bên trong, một phẩm chất mà rất nhiều giáo viên than phiền rằng học sinh thiếu. Nếu vậy, tại sao tất cả giáo viên không đảm bảo rằng mỗi bài học đều gắn kết sự hứng thú của học sinh? Nhung nhà giáo ở EduCon cũng vô cùng nhanh chóng phản hôii: việc thiết kế hướng dẫn cho một nhóm đa dạng học sinh quả thực khó; việc thuyết phục học sinh về giá trị dài hạn của bài tập khi mà những nhu cầu ngắn hạn thì đang hiện hữu cũng khó; và đương nhiên, nhiều giáo viên còn bị hạn chế bởi chương trình, tiêu chuẩn và những kì kiểm tra.

Chase và Laufenberg nghĩ rằng việc nghĩ rằng việc đưa lý thuyết về động lực có thể một cách dễ tiếp cận để giúp giáo viên tìm những con đường dẫn tới cách nhận thức hay gắn kết mà có thể mang lại động lực học tập. Tóm lại, các tình huống có thể mang lại động lực hoặc có thể không. Điều này sẽ dễ hiểu đối với những ai đã từng chứng kiến học sinh vật lộn trong lớp, bỏ cuộc và mất tự tin; đổi lại nhìn thấy chúng luyện tập một môn thể thao, nhận được phản hồi tự huấn luyện viên và vẫn tích cực sau một trận thua. Rằng học sinh cảm thấy có động lực đối với một thể thao của chúng nhưng không ở trong lớp.

Có 4 yếu tố chung trong những tình huống tạo động lực mà chính là: lựa chọn, thử thách, hợp tác và kiểm soát.

\section{LƯ'A CHON}

Về mặt định luật, lựa chọn là thứ mang tính bản năng. Mọi người luôn có xu hướng hứng thú hơn với những thứ mà họ được quyền chọn. Nhưng lựa chọn cũng có thể trở nên hồn độn với nhóm nhiều học sinh. Kể cả vậy, đây vẫn là điểm đơn giản nhất để bắt đầu.

Giáo viên Tiếng Anh cấp 3 Tiffany Greenberg đã phát bực với mỗi lần cô giao bài tập đọc và học sinh đến lớp ngày hôm sau, không chuẩn bị bài để thảo luận. Việc đó khiến cho cô chuyển phần lớn việc đọc bài lên lớp, và kể cả vậy thì học sinh cũng rất miễn cưỡng hoàn thành.

'Một trong những khó khăn lớn nhất của tôi là khiến chúng chịu đọc bài trong lớp' Greenberg nói. Vì vậy, trong lớp hồi ký, cô quyết định cho học sinh chọn sách mình sẽ đọc. Cô chọn những tài liệu ngắn hơn làm sách dẫn dắt và cho chúng chọn những cuốn sách chúng muốn trong thời gian đọc im lặng.

'Điều tôi yêu thích về việc này là đối với một số đứa trẻ trong lớp, đây là lần đâu chúng đọc sách' cô nói. Cô cũng cho chúng chọn cách để trình bày những gì đã đọc, hơn là bắt chúng phải viết một bài luận.
'Zac [Chase] đã khuyến khích tôi, với vai trò giáo viên nên làm ít hơn để học sinh làm nhiều hơn và từ đó, chúng sẽ học được nhiều hơn'

Cuối năm, cô đã khảo sát học sinh của mình và kết quả cho thấy hầu như tất cả học sinh đều thích được có sự lựa chọn trong việc học tập.

‘Đi kèm với những sự lựa chọn của học sinh vẫn phải là kỳ vọng và sự dẫn dắt,' Greenberg chia sẻ. 'Vẫn cần phải có những sự kiểm tra và cân bằng trong lớp học.' Ví dụ, cô ấy đang thử nghiệm cách hỏi học sinh thực hiện những nghiên cứu ban đầu về một chủ đề mới và chỉ lên giảng bài để hỗ trợ thêm những chi tiết mà cô nghĩ học sinh đã bó sót khi tìm kiếm trong nghiên cứu. Có một yếu tố của sự lựa chọn ở đó , nhưng cô cũng đang tận dụng sự chủ động của học sinh, trong khi thể hiện rằng cô ấy tin tướng họ. Cô ấy cũng sử dụng đây như là một cơ hội để dạy về thế nào mà nguồn tìm kiếm đang tin cậy.

'Tôi cảm thấy như vậy, học sinh nắm bắt các khái niệm tốt hơn nhiều', cô nói. 'Và học sinh của tôi nêu rõ rằng chúng cũng chán việc phải ngôii im nghe giáo viên nói cả buổi'

Thường thì giáo viên sẽ sợ có sự lựa chọn bởi họ không tin rằng học sinh không có khả năng chọn lựa một cách sáng. Hoặc họ lo lắng rằng nó sẽ làm lớp học vượt ngoài tâm kiểm soát. Và dù đó là những nỗi sợ hợp lý, việc chỉ cần thử chúng cũng đem lại nhiều điểm tích cực.

'Càng cho phép nhiều quyền lựa chọn, tôi lại biết càng ít về những gi một đứa trẻ sẽ làm khi được lựa chọn, và càng ít tôi biết về khà năng thực tế của chúng,' 
Chase nói. Và nếu mọi đứa trẻ đều làm cùng một thứ thì trẻ đang gặp khó khăn sẽ nổi bật so với lớp. Nhưng nếu mỗi đứa trẻ được chọn quyền thể hiện kiến thức của chúng theo một cách khác nhau, thì việc học sẽ không chỉ trở nên thu hút mà sự khác biệt sẽ trở nên khó nhận diện hơn nhiều. Giáo viên có thể sẽ vẫn biết bao nhiêu tư duy đã được dành cho sản phẩm nhưng bạn cùng lớp thì có thể không.

\section{THỬ THÁCH}

'Chúng tôi luôn muốn loại bỏ những thách thức,' Laufenberg nói. 'Nhưng khi chúng ta làm như vậy thì chúng ta đã đồng thời loại bỏ một yếu tố lớn mà làm điều gì đó trở nên thú vị.' Việc đánh giá thử thách như thế nào là vừa đủ có thể khó, nhưng Chase và Laufenberg khuyên các vị giáo viên nên kết luận rằng trẻ con có đủ khả năng hơn chúng ta nghĩ. Việc bắt một đứa trẻ phải vật lộn quá nhiều có thể không tốt nhưng hãy làm quen với ý nghĩ rằng chúng có thể giải quyết được nhiều thử thách hơn ta nghĩ.

'Và nếu bạn là một lãnh đạo trường học, hãy đối xử tương tự với giáo viên,' Chase nói. 'Tin vào sự đủ khả năng'

Một cách để giúp giáo viên tự nhắc nhở bản thân về khả năng của học sinh là để họ tham gia vào các lớp học trên lớp học đang dạy. Như vậy một vài học sinh có thể quen thuộc và nhìn thấy sự trưởng thành mà họ đã đóng góp trong một năm có thể truyền cảm hứng.

Chase công nhận rằng xu hướng diu dắt kỹ của giáo viên thường đến từ một nơi yêu thương, nhưng mỗi khi anh nghe thấy giáo viên nói rằng học sinh của họ không làm được điều gì, anh đơn giản trả lời 'đó là lý do chúng ta ở đây'

\section{HỚP TÁC}

Trong những năm gần đây đã có rất nhiều thảo luận vể hợp tác như là một kĩ năng học sinh cần học để phục vụ cho công việc sau này. Và mặc dù điều đó đúng, sự hợp tác cũng tạo động lực. Trẻ em là những (beings?) xã hội và chúng học được nhiều về thế giới và kiến thức bằng cách trao đổi với nhau.

Digsby, một giáo viên lớp một, đã cố gắng thêm sự hợp tác vào trong bài giảng của minh nhiêu hơn. Cô thường bắt đầu lớp bằng việc yêu cầu học sinh thảo luận theo đổi và sau đó, hai nhóm một sẽ hợp tác và cùng làm việc với nhau.
Trong một bài tập, Digsby yêu cầu các nhóm thiết kế một sản phẩm haowjc dịch vụ để giúp giáo viên có lại được giờ ăn trưa của họ. 'Nghe được những thảo luận hoặc hợp tác giữa chúng, dù chúng mới chỉ có sáu, bảy tuổi, về các chúng sẽ thực hiện hoá sản phẩm của mình rất có ích không chỉ cho chúng mà còn cho bản thân tôi'. Cô chia sẻ.

Cô cũng nhận thấy những khoảnh khắc nhỏ của sự hợp tác có thể thúc đây học sinh. Trong lớp học của cô, một cậu bé học tốt có thể làm bạn với một cậu bé khác đang gặp khó khăn trong lớp. Việc bạn cậu thường nói với những thứ minh đang học có thể giúp nhắc lại kiến thức.

Trong quá khứ khi học sinh làm việc cùng nhau, Digsby thường lo lắng về việc học sinh nhắc bài nhau. 'Tôi đã có tư duy như vậy', cô nói. 'Nhưng sau đó tôi chợt nhận ra rằng, 'đợi một chút, nếu tôi dạy cho chúng hướng dẫn lâ̂n nhau chúng có thể học được rất nhiều từ bạn của chúng bên cạnh tôi.'

Chase và Laufenberg đã đưa ra những cách thật đơn giản để đưa sự hợp tác vào trong lớp học. Giáo viên có thể yêu cầu hai học sinh cùng kiểm tra bài của nhau trước khi nộp bài cũng là một ví dụ.

Một ý tưởng khác, yêu cầu học sinh phải trích dẫn nhau khi tự suy ngẫm lại sau khi nộp bài. Việc này sẽ giúp phát triển sự tự lập, hứng thú, và cho phép học sinh được làm chủ việc các em làm việc với ai và như thế nào.

\section{KIỂM SOÁT}

Một cách để giáo viên trung học toán và khoa học Keith Kennison khuyến khích học sinh tự chủ hơn trong việc học của các em bằng việc dạy học sinh đặt câu hỏi.

'Nếu học sinh là những người đang đưa ra câu hỏi thì đó là một bước ngoặt lớn,' Kennison chia sẻ. 'Nếu họ đang tự khám phá điều gì đó tôi có thể giúp dẫn dắt học.'

Anh nhận thấy sự lựa chọn, thách thức, hợp tác và tự chủ được kết hợp hài hoà trong lớp học của mình. Anh dành thời gian đầu năm học để nói về việc toán là một nghĩa vụ xã hội và rằng 'bất kể chủ đề thú vị nào mà chúng ta khám phá cũng sẽ có phần thách thức. Và khi bạn đang khám 
phá những chủ đề đó, việc gặp cản trở là đương nhiên.'

Học sinh không luôn tin anh ngay nhưng anh giúp học sinh của mình khám phá dần bản thân bằng cách sử dụng bản đồ tư duy. Trong lớp, học cùng nhau thảo luận về cách mà các nhà toán học kết nối những thứ học đã biết, và lên kế hoạch tìm hiểu những khái niệm mới ra sao và đánh giá kết quả công việc của họ như thế nào. Kennison yêu cầu học sinh tự thiết kế bản đồ tư duy của chính họ.

'Tôi dành nhiều thời gian giúp đỡ bọn trẻ nghĩ về cách tư duy cần để vượt qua và đạt được một thứ gì đó đáng giá,' anh nói. Đó là một quá trình chậm và từ từ, nhưng trong quá trình đó, anh sẽ làm học sinh của mình quen dần với việc tìm đến các bạn mình khi gặp vấn đề thay vì tìm đến anh. 


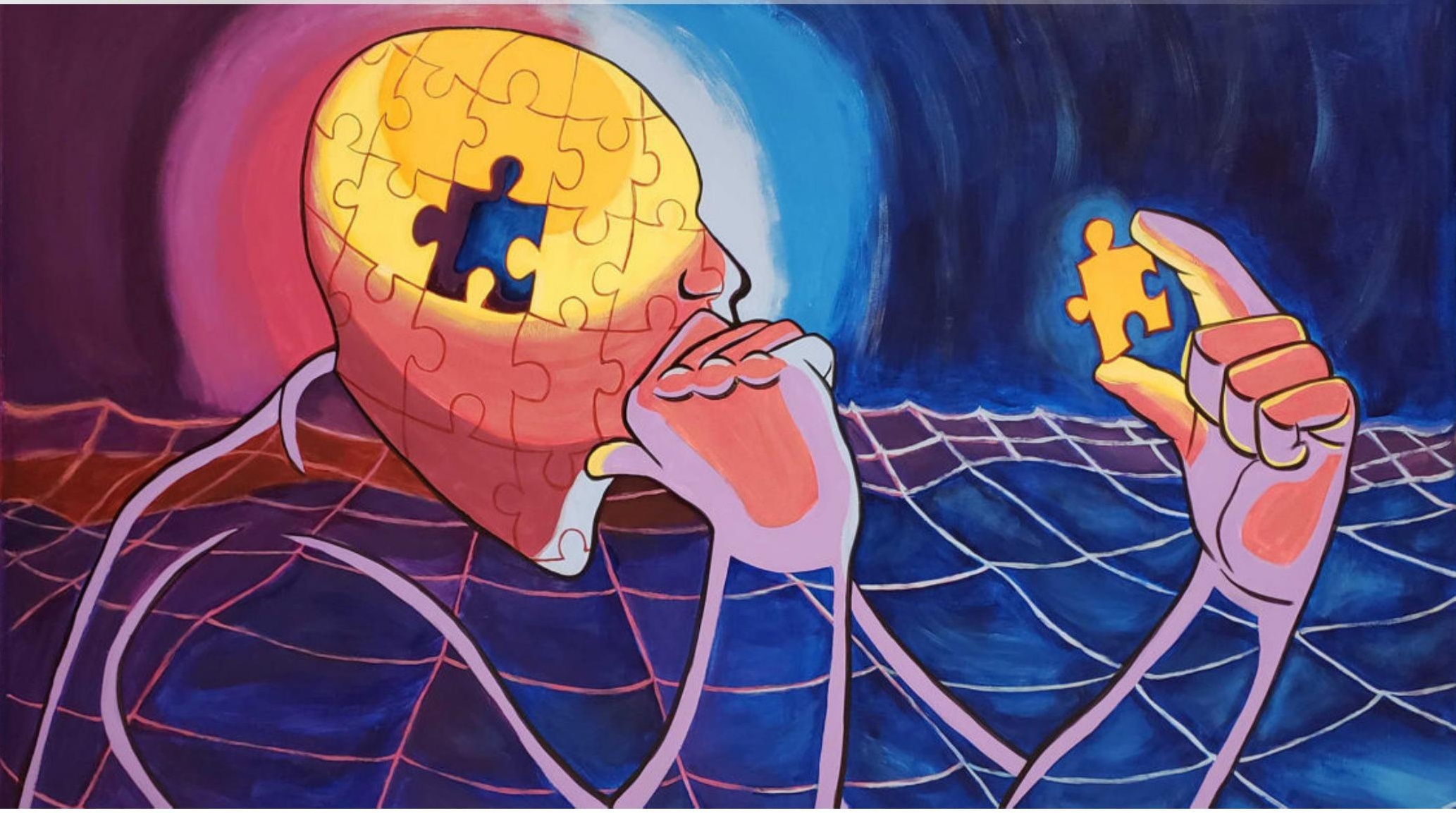

4 GIAI ĐOA.N PHÁT TRIỂN NHÂNN THỨC -

NỀN TẢNG VÀ CÁC K'HÁI NIỆM CHÍNH TRONG LÝ THUYẾT CÜA PIAGET

Kendra Cherry I Pomona dịch

Lý thuyết về sự phát triển nhận thức của Jean Piaget cho thấy rằng trẻ em tiến triển qua 4 giai đoạn phát triển tâm trí. Lý thuyết của ông không chỉ tập trung vào việc hiểu cách trẻ em chiếm lĩnh tri thức mà còn hiểu được bản chất của trí thông minh. 4 giai đoạn đó của Piaget là:

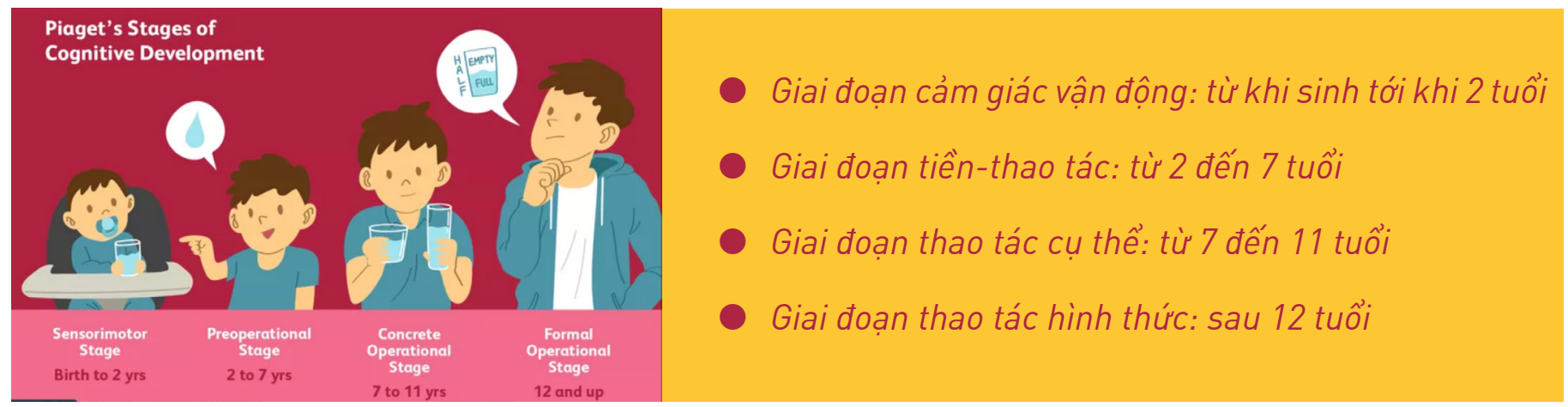

Piaget tin tưởng rằng trẻ em đóng vai trò tích cực trong tiến trình học tập, hành động như những nhà khoa học nhỏ khi các em thực hành những thí nghiệm, quan sát và tìm hiểu thế giới này. Khi trẻ em tương tác với thếgiới xung quanh minh, các em liên tục nạp thêm hiểu biết, vun đắp những tri thức sẵn có và điều chinh những ý niệm cũ để thích ứng được với những thông tin mới.

Nguôn: https://www.verywellmind.com/piagets-stages-of-cognitive-development-2795457\#how-piaget-developed-the-theory 


\section{PIAGET BÃ PHÁT TRIỂN LÝ THUYẾT NÀY NHU THẾ NÀO?}

Piaget sinh tại Thụy Điển vào cuối những năm 1800 và là một học sinh phát triển sớm, từng xuất bản bài báo khoa học đầu tiên khi mới chỉ 11 tuổi. Ông được làm quen khá sớm với sự phát triển trí tuệ của trẻ em khi làm trợ lý cho Alfred Binet và Theodore Simon trong thời gian họ làm nghiên cứu nhằm chuẩn hóa bài kiểm tra $I Q$ nổi tiếng của họ.

Hầu hết mối quan tâm của Piaget về sự phát triển nhận thức ở trẻ được lấy cảm hứng qua những quan sát từ chính cháu trai và con gái của ông. Những quan sát này củng cố giả thuyết của ông rằng tâm trí của trẻ em không chỉ đơn thuần là bản sao nhỏ hơn của tâm trí người lớn.

Cho tới thời điểm này trong lịch sử, trẻ em vẫn được đối xử như một bản sao thu nhó của người lớn. Piaget là một trong số những người đâu tiên xác định được rằng cách trẻ em suy nghĩ khác với cách người lớn suy nghĩ.

Thay vào đó, ông đề xuất rằng trí thông minh dần phát triển và mở mang thông qua một chuỗi các giai đoạn. Ông cũng cho rằng những em lớn tuổi không hề suy nghĩ nhanh hơn những em bé ít tuổi hơn. Thay vì thế, có sự khác biệt cả về chất cũng như về lượng trong cách tư duy giữa trẻ em nhỏ tuổi so với những em lớn tuổi hơn.

Dựa trên những quan sát của mình, ông kết luận rằng trẻ em không hể kém thông minh hơn người lớn, chỉ là các em suy nghĩ khác so với người lớn. Albert Einstein gọi khám phá của Piaget là: "quá đơn giản đến mức chỉ có thiên tài mới có thể nghĩ ra được cách làm này."

4 giai đoạn phát triển của Piaget mô tả sự nhận thức của trẻ em. Sự phát triển nhận thức bao gồm những thay đồi của quá trình nhận thức và các năng lực. Trong quan điểm của Piaget, sự phát triển nhận thức đầu đời bao gồm những quá trình dựa trên hành vi và sau đó tiến tới những thay đổi trong các hoạt động của tâm trí.

\section{NHŨNG GIAI ĐOẠN}

Thông qua việc quan sát những đứa trẻ của minh, Piaget đã phát triển một lý thuyết về giai đoạn của sự phát triển trí tuệ bao gồm 4 giai đoạn riêng biệt:

\section{Giai đoạn cám giác vận động}

Tuổi: Từ khi sinh ra cho tới khi lên 2

Các đặc điểm chính và những thay đổi phát triển:

- Trẻ em sơ sinh nhận biết được thế giới thông qua những cử động và các cảm giác vận động.

- Trẻ em tim hiểu về thế giới thông qua những hành động cơ bản như là: bú mút, nắm bắt, nhìn ngắm, và lắng nghe.

- Trẻ sơ sinh học được rằng các vật tiếp tục tôn tại ngay cả khi chúng không thể được nhin thây nữa (vật thường trực: object permanence).

- Các em là con người riêng biệt với những người khác và những vật thể khác ở xung quanh minh.

- Các em nhận ra rằng những hành động của bàn thân có thể gây ra các vấn đề mới trong thế giới xung quanh minh.

Trong suốt giai đoạn sớm nhất của sự phát triển nhận thức, những em bé sơ sinh và những em đang ở tuổi tập đi sẽ chiếm lĩnh tri thức thông qua các trải nghiệm của cảm giác vận động và qua việc thao tác trên đồ vật. Toàn bộ những trải nghiệm sớm nhất của một đứa trẻ trong giai đoạn này diễn ra thông qua những phản xạ, cảm giác và phản ứng vận động cơ bản.

Chính ở giai đoạn cảm giác vận động, trẻ em trải qua một thời kỳ phát triển và học tập đầy ấn tượng. Khi tương tác với môi trường xung quanh, trẻ em liên tục phát hiện những khám phá mới về cách mà thế giới này vận hành.

Sự phát triển nhận thức diễn ra ở thời kỳ này xảy ra trong thời gian tương đối ngắn và bao gôm một sự tăng trướng vượt trội. Trẻ em không chỉ học cách để thực hiện những hành động thể chất như là bò và đi; mà còn học được một lượng ngôn ngữ dồi dào từ những người mà các em tương tác với. Piaget cũng đã chia giai đoạn này làm các tiểu giai đoạn khác nhau. ở thời kỳ cuối của giai đoạn cảm giác vận động, tư duy biểu trưng bắt đầu xuất hiện.

Piaget tin rằng sự thường trực của vật hay tính 
cố định của vật, cái hiểu biết rằng sự vật vẫn tôn tại ngay cả khi chúng không được nhin thây, là một yếu tố quan trọng tại thời điểm phát triển này.

Bằng cách khám phá ra rằng sự vật là những thực thể riêng rẽ, khác biệt và sự vật tôn tại tự thân nằm ngoài nhận thức của mỗi cá nhân, trẻ em sau đó bắt đầu có khả năng gán tên và các từ cho các sự vật.

\section{Giai đoạn tiền thao tác}

Độ tuổi: Từ 2 đến 7 tuổi

Các đặc điểm chính và những thay đổi phát triển:

- Trẻ em bắt đầu tư duy một cách biểu tượng và học cách sử dụng từ ngữ, hình ảnh để tượng trưng cho sự vật.

- Trẻ em ớ giai đoạn này có xu hướng coi minh là trung tâm và khó khăn với việc nhìn nhận sự việc từ góc nhin của người khác.

- Trong khi các em đang tiến bộ hơn trong ngôn ngữ và tư duy, các em vẫn có xu hướng suy nghĩ về mọi thứ theo những cách rất cụ thể.

Những nền tảng của sự phát triển ngôn ngữ có lẽ đã được thiết lập từ giai đoạn trước đó, nhưng sự xuất hiện của ngôn ngữ là một trong những dấu hiệu chính của sự phát triển giai đoạn tiền thao tác. ${ }^{1}$

Trẻ em ở giai đoạn phát triển này đã khéo léo hơn khi chơi trò đóng vai, nhưng vẫn tiếp tục suy nghĩ rất cụ thể về thế giới xung quanh minh.

Ở thời kỳ này, trẻ em học thông qua những trò chơi sắm vai nhưng vẫn khó khăn với logic và với việc tiếp nhận quan điểm của người khác. Các em vẫn thường gặp khó khăn trong việc hiểu ý niệm về tính bất biến.

Ví dụ, một nhà nghiên cứu lấy một miếng đất sét, chia nó thành hai phần bằng nhau, sau đó cho đứa trẻ chọn một trong hai miếng để chơi. Một miếng đất sét thì đã được vo tròn, trong khi miếng còn lại được làm phẳng ra giống hình dạng của một chiếc bánh pancake. Vì miếng bánh dẹt trông rộng hơn, nên đứa trẻ đang ở giai đoạn tiền vận động có vẻ sẽ chọn lấy miếng đó, cho dù hai miếng thực ra có kích thước ngang nhau.

\footnotetext{
1 Scott HK. Piaget. StatPearls [Internet]. Published
} June 1, 2019.

\section{Giai đoạn thao tác cự thể}

Tuổi: từ 7 tới 11 tuổi

Các đặc điểm chính và những thay đổi phát triển:

- Ở giai đoạn này, trẻ em bắt đầu suy nghĩ một cách logic về những sự việc cự thể.

- Các em bắt đâuu hiểu khái niệm về sự bảo toàn; ví dụ như lượng chất lỏng trong một chiếc cốc thấp và rộng là ngang bằng với lượng chất lóng trong một chiếc ly cao và hẹp.

- Tư duy của các em trở nên có logic và có tổ chức hơn, nhưng mà vẫn rất cụ thể.

- Trẻ em bắt đâu sử dụng logic quy nạp hoặc suy luận từ thông tin cụ thể tới những nguyên lý chung.

Trong thời điểm phát triển này, khi mà trẻ vẫn đang tư duy rất cụ thể và theo nghĩa đen thì các em trở nên thành thục hơn với tư duy logic. Việc cho mình là trung tâm của giai đoạn trước đó bắt đầu dần biến mất vì các em đang dần tốt hơn trong việc hiểu được cách mà mọi người có thể nhìn nhận về một tình huống.

Trong khi tư duy dần trở nên logic hơn rất nhiều ở giai đoạn thao tác cụ thể, thi nó cũng có thể trở nên rất cứng nhắc. Trẻ em ở giai đoạn phát triển này có xu hướng gặp khó khăn với các khái niệm trừu tượng và các khái niệm giả định.

Ở giai đoạn này trẻ em cũng dần bớt coi mình là trung tâm và dần nghĩ về cách mà mọi người có thể suy nghĩ hay cảm nhận. Trẻ em ở giai đoạn thao tác cụ thể cũng dần hiểu được rằng suy nghĩ của mình là duy nhất đối với bản thân mình và không phải ai cũng cần thiết chia sẻ những suy nghĩ, cảm xúc hay ý kiến.

\section{Giai đoạn thao tác hinh thức}

Tuổi: Từ 12 tuổi trở lên

Các đặc điểm chính và những thay đổi phát triển:

- Ở giai đoạn này, những em đang ở tuổi thanh niên hoặc đang ở tuổi mới lớn bắt đầu tư duy một cách trừu tượng và suy luận về các vấn đề giả định.

- Tư duy trưu tượng xuất hiện

- Các thanh thiếu niên bắt đâu nghĩ nhiều hơn về luân lý, triết học, xã hội các vấn đề chính trị đòi hỏi suy luận trừu tượng và lý thuyết.

- Bắt đầu sử dụng logic hoặc suy luận diễn dịch từ nguyên lý chung tới các thông tin cụ thể. 
Giai đoạn cuối cùng trong lý thuyết của Piaget có liên quan tới sự gia tăng của logic, khả năng sử dụng suy luận diễn dịch và hiểu biết về những ý tưởng trừu tượng. Ở giai đoạn này, người ta trở nên có khả năng nhìn thấy nhiều giải pháp tiềm năng cho các vấn đề và suy nghĩ khoa học hơn về thế giới xung quanh.

Khả năng suy nghĩ về các ý tưởng và tình huống trừu tượng chính là dấu hiệu nhận biết chính ở giai đoạn thao tác hinh thức của sự phát triển nhận thức. Khả năng lên kế hoạch một cách có hệ thống cho tương lai và suy luận về những tình huống giả định cũng là những năng lực xuất hiện ở giai đoạn này.

Điều quan trọng là phải lưu ý rằng Piaget không nhìn nhận sự phát triển nhận thức của trẻ em như là một quá trình về lượng. Vậy đó, trẻ em không chỉ nạp thêm thông tin hay kiến thức vào tri thức sẵn có của mình khi chúng lớn lên. Thay vì vậy, Piaget gợi ý rằng có một sự thay đổi về chất trong cách mà trẻ em suy nghĩ khi mà các em dần trải qua bốn giai đoạn này. Một đứa trẻ ở tuổi lên 7 không chỉ có thêm thông tin về thế giới hơn chính nó lúc 2 tuổi, mà còn có một sự thay đổi nền tảng trong cách đứa bé đó tư duy về thế giới.

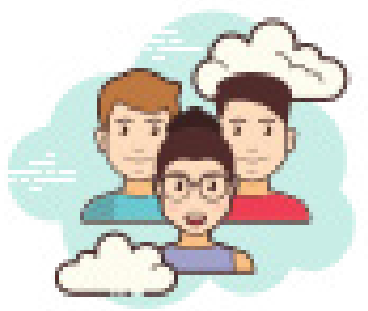

\section{NHŨNG KHÁI NIỆM QUAN TRỌNG}

Để hiểu hơn về những gì diễn ra trong sự phát triển nhận thức, điều quan trọng là cần phải xem xét một vài ý tưởng và các khái niệm quan trọng đã được Piaget giới thiệu.

Dưới đây là một vài yếu tố ảnh hưởng tới cách trẻ em học hỏi và lớn lên:

\section{Cấu trúc sơ khai (Schemas)}

Một cấu trúc sơ khai diễn tả cả tác động thể chất lẫn tâm trí trong sự hiểu và biết. Cấu trúc sơ khai là những phạm trù kiến thức giúp chúng ta giải nghĩa và hiểu về thế giới.

Trong quan điểm của Piaget, một cấu trúc sơ khai bao gồm cả những phạm trù kiến thức và quá trình chiếm lĩnh kiến thức đó. Khi các trải nghiệm diễn ra, những thông tin mới này được sử dụng để sửa đổi, thêm vào hoặc thay thế những cấu trúc sơ khai trước đó.

Ví dụ, một đứa trẻ có một cấu trúc sơ khai về một loài động vật, chẳng hạn như con chó. Nếu đứa trẻ chì có trải nghiệm duy nhất với những chú chó nhỏ, đứa trẻ đó có thể tin rằng tất cả những con chó đều bé tí tẹo, có lông và có 4 chân. Giả sử sau đó đứa trẻ gặp phải một con chó to lớn. Nó sẽ tiếp nhận thông tin mới này, sửa các cấu trúc sơ khai đã có trước đó để bao gồm thêm những quan sát mới mẻ này.

\section{2. Đồng hóa}

Quá trình nạp thông tin mới vào các cấu trúc sơ khai sẵn có được biết tới là sự đồng hóa. ${ }^{2}$ Quá trình này có phần chủ quan bởi vì chúng ta có xu hướng sửa đổi các trải nghiệm và thông tin một chút để nó trở nên phù hợp với niềm tin sẵn có của chúng ta. Trong ví dụ trên, việc nhìn thấy một chú chó và dán nhãn nó là "chó" là một trường hợp của việc đồng hóa con vật đó vào trong cấu trúc sơ khai về loài chó của đứa trẻ.

2 Theo Piaget, có hai hiện tượng đồng hóa: Đồng hóa Phổ cập hóa (assimilation généralisatrice) là quá trinh tích nhập các đối tượng rộng lớn hơn vào cấu trúc sơ khai phản xạ. Và Đồng hóa Nhận ra (assimilation récognitive) là hình thức diễn ra trong quá trinh lặp lại phản xạ mà có một số dạng điều kiện khác biệt, sinh ra một sự phân biệt thực tế. (Tham khảo thêm cuốn "Sự ra đời trí khôn ở trẻ em" của Jean Piaget do Hoàng Hưng dịch) - chú thích của người dịch. 


\section{3. Điều tiết}

Một phần khác của sự thích nghi bao gồm thay đổi hoặc thay thế các cấu trúc sơ khai đang tôn tại bởi thông tin mới được biết tới là quá trình điều tiết. Sự điều tiết bao gồm sửa đổi các cấu trúc sơ khai hay các ý niệm sẵn có, như một kết quả của một trải nghiệm mới hay một thông tin mới. Một cấu trúc sơ khai mới cũng có thể được hình thành trong quá trình này.

\section{Cân bằng}

Piaget tin rằng mọi đứa trẻ cố gắng có được sự cân bằng giữa sự đồng hóa và điều tiết, đạt được thông qua một cơ chế được Piaget gọi là cân bằng. Khi đứa trẻ tiến bộ qua các giai đoạn phát triển nhận thức, điều quan trọng là phải giữ được sự cân bằng giữa việc áp dụng những kiến thức trước đây (đồng hóa) và thay đổi hành vi để giải thích kiến thức mới (điều tiết). Sự cân bằng giúp giải thích cách trẻ chuyển từ một giai đoạn tư duy tới giai đoạn tiếp theo.

Đôi lời từ Verywell

Một trong số những yếu tố quan trọng nhất về lý thuyết của Piaget để ghi nhớ đó là việc tiếp nhận quan điểm rằng việc tạo dựng kiến thức mới và trí thông minh vốn là một quá trình tích cực.

“Bản thân tôi phản đối ý kiến cho rằng tri thức là một sự sao chép thụ động của thực tế”, Piaget giải thích. "Tôi tin rằng biết một đối tượng có nghĩa là phải làm theo nó, tạo dựng một biến đổi hệ thống mà có thể thực hiện trên nó hoặc cùng với sự vật đó. Nhận thức được thực tế có nghĩa là xây dựng những hệ thống của sự thay đổi mà tương ứng, phù hợp nhiều hay ít hơn so với thực tế."

Lý thuyết về sự phát triển nhận thức của Piaget làm đầy thêm hiểu biết của chúng ta về dự phát triển trí tuệ của trẻ. Đồng thời nhấn mạnh rằng trẻ em không chi đơn thuần là người tiếp thụ tri thức. Mà thay vào đó, trẻ em luôn khám phá và thử nghiệm khi các em xây dựng hiểu biết của mình về cách thế giới vận hành.

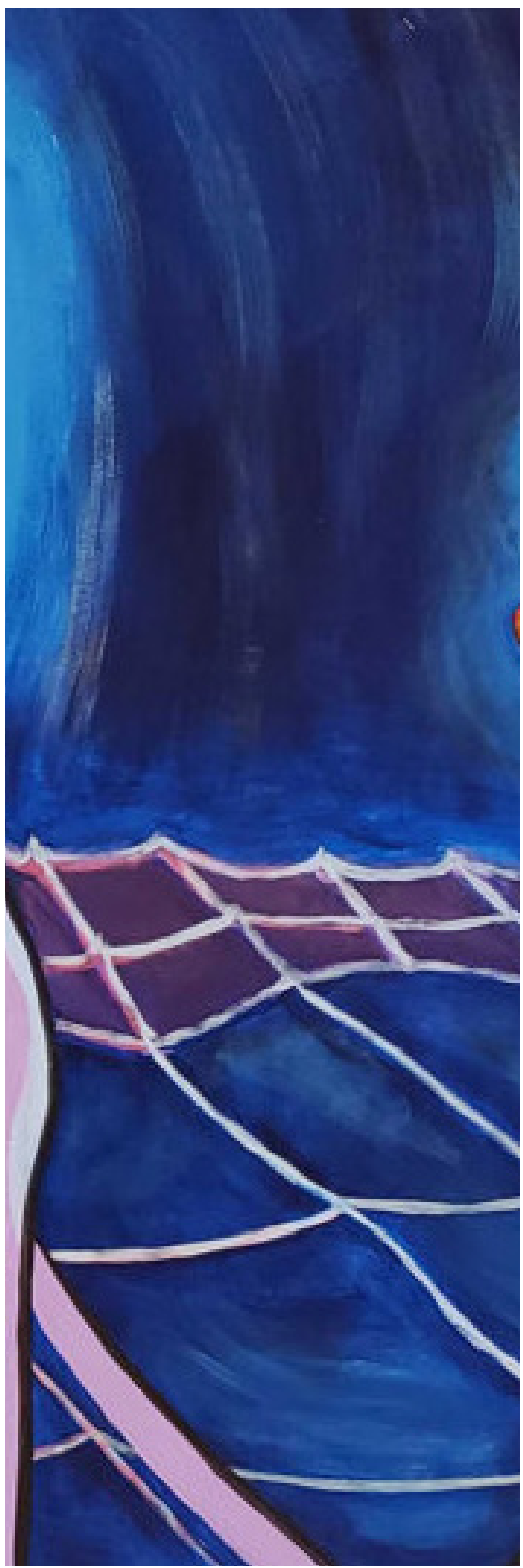




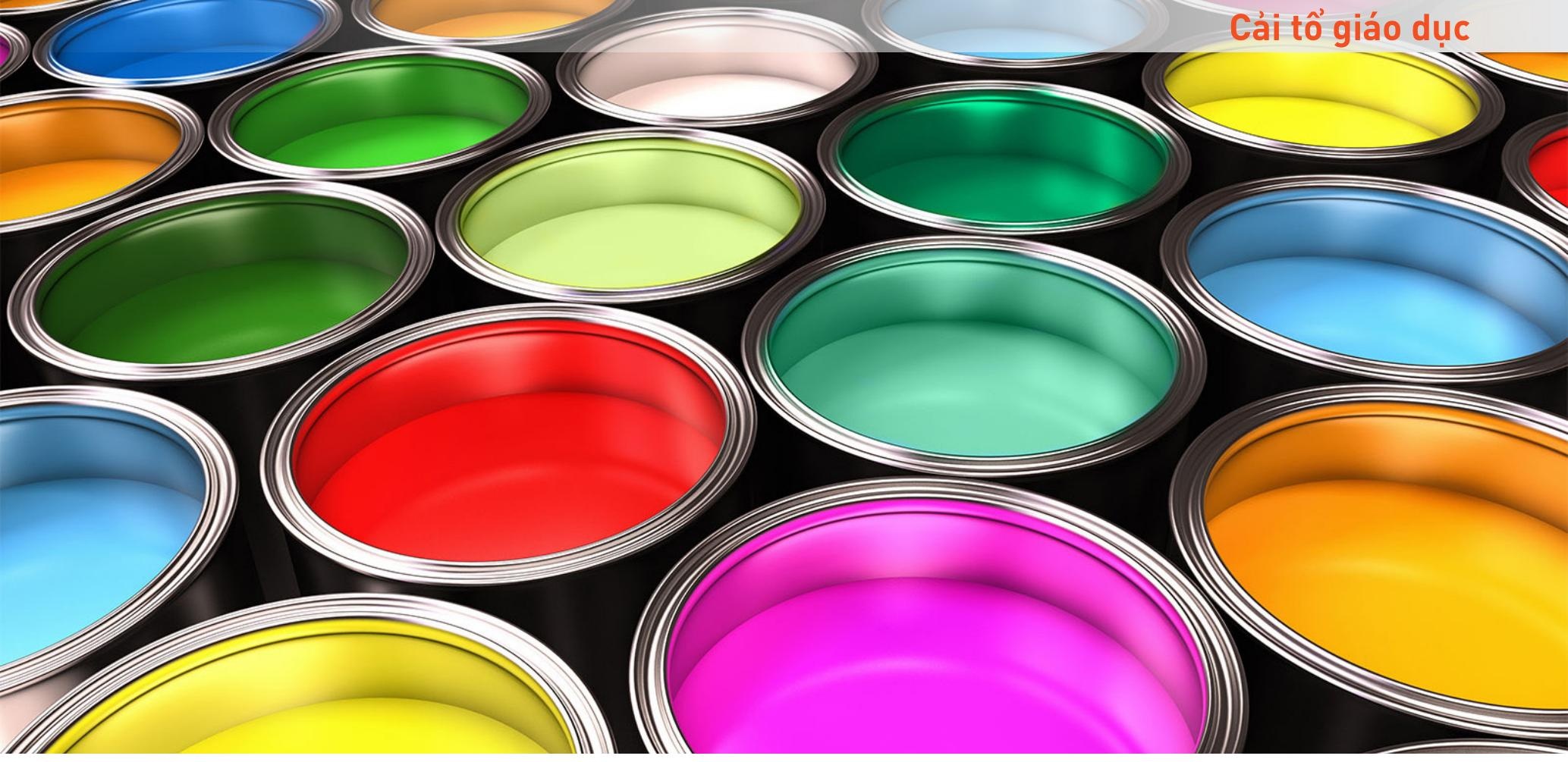

[30ะ FRAMEWORKS GIÁO DỤC] - KỲ 7 -

\section{KHUNG GIÁ TRI PHÁT TRIỂN DA - DEVELOPMENTAL ASSETS FRAMEWORK}

Đức Hoàng

Phát triễn bởi Search Institute

\section{Mục dích:}

Xác định các cấu thành chính yếu của quá trình phát triển lành mạnh, giúp tré em lớn lên khoẻ mạnh, biết quan tâm và có trách nhiệm.

Dộ tuối: 3 5; 5 9; 8 12; 12 18

Áp dụng: Kể từ năm 1990, khung DA là một trong những đề xuất về SEL được phổ biến và trích dẫn nhiều nhất trên thế giới, được dịch ra 29 ngôn ngữ và ứng dụng trong nhà trường, gia đình, cộng đồng, các hoạt động ngoài giờ học lout-ofschool time)

Khung này tập trung vào một tập hợp các vốn quý bên trong (sức mạnh cảm xúc xã hội, giá trị và cam kết) và bên ngoài (mối quan hệ và cơ hội) có ảnh hướng đến sự phát triển của trẻ em, thanh thiếu niên và hỗ trợ họ trở thành người trưởng thành chu đáo, có trách nhiệm và hiệu suất.

\section{Bối cánh:}

- Ghi nhận rằng văn hoá, bối cảnh và kinh nghiệm tác động đến cách thanh thiếu niên phát triển và trải nghiệm các vốn sống.

- Làm nổi bật những thế mạnh và thách thức độc đáo giữa các nhóm dân cư khác nhau, đặc biệt tập trung vào thanh thiếu niên da màu và LGBT. - Được phát triển bằng cách sứ dụng thông tin khảo sát từ gần 6 triệu trẻ em và thiếu niên ở Hoa Kỳ và trên toàn cầu.

- Cho thấy sự hiện diện và phát triển các vốn sống giúp làm giảm thiểu các hành vi rủi ro và thúc đẩy sự trường thành.

\section{Tài liệu tham khào:}

* Search Institute (2005). 40 Developmental Assets for Early Childhood lages 3-5). Retrieved from: http://v.fastcdn.co/u/73824624/357827310-3-5-English25580211-.pdf.

* Search Institute (2009). 40 Developmental Assets for Children Grades K-3 (ages 5-9). Retrieved from: http://v.fastcdn.co/u/73824624/357827210-5-9-English25580191-.pdf.

* Search Institute (2006). 40 Developmental Assets for Middle Childhood lages 8-12). Retrieved from: http://v.fastcdn.co/u/73824624/357827060-8-12-English25580171.pdf.

* Search Institute (2006). 40 Developmental Assets for Adolescents (ages 12-18). Retrieved from: http://v.fastcdn.co/u/73824624/357826910-12-18-English2557998.pdf.

\section{\#EdLab}

\#moingay1frameworkGiaoduc \#LearnToLearn \#CultivatingEducationalPractices 


\section{Cải tổ giáo dục}
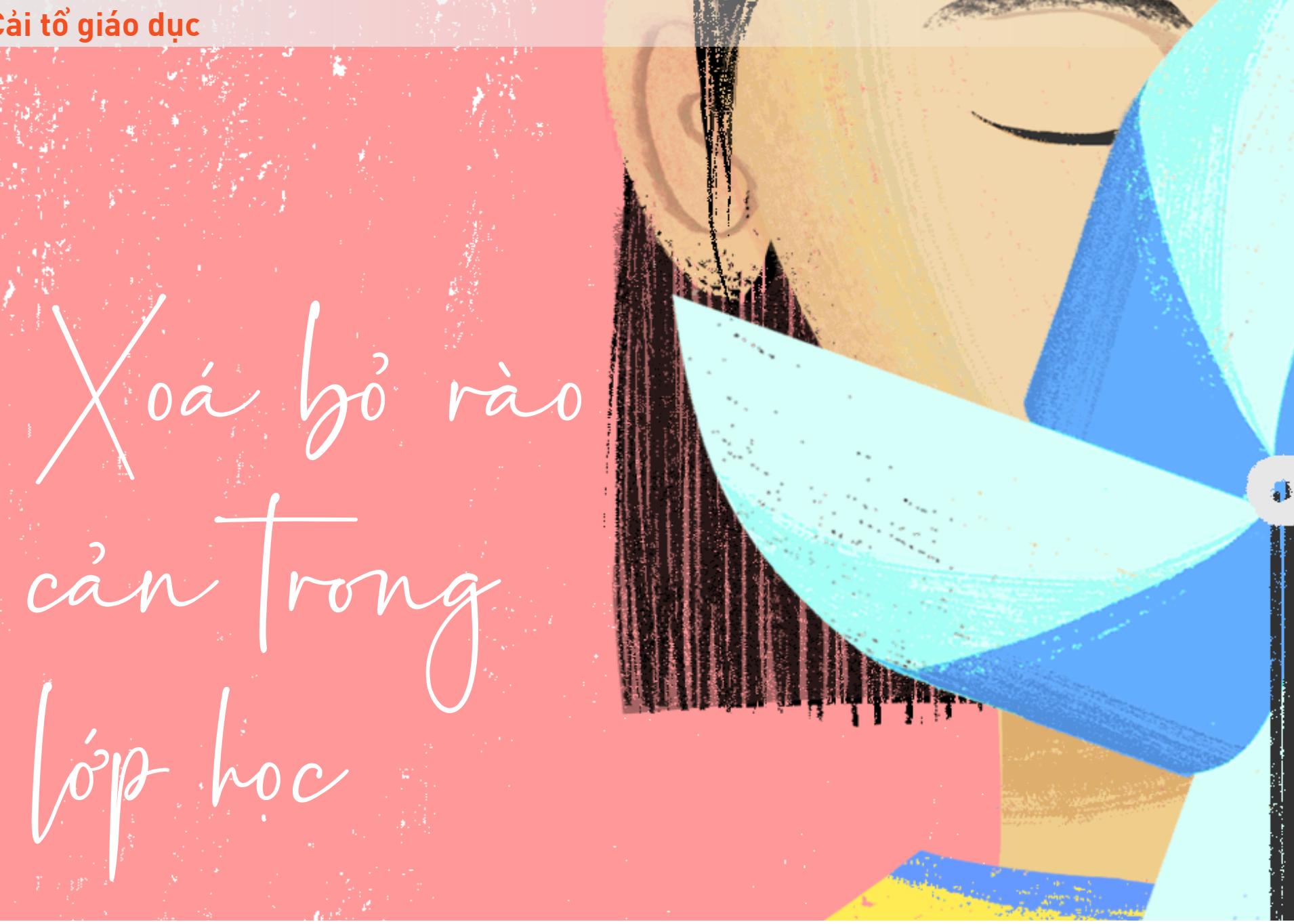

Tôi đã không thể tin vào may mắn của mình trong những ngày đầu tiên bắt đầu năm học mới. Học sinh của tôi tham gia hăng hái trong các hoạt động học tập, làm việc nhóm tốt và tuân thủ mọi thỏa thuận của chúng tôi trong lớp học. Với những điều tốt lành chồng chất, tôi chắc chắn rằng đây sẽ là năm học tốt nhất của tôi từ trước cho đến nay. Tuy nhiên, sau 3-4 tuần, các hành vi tốt trên giảm dần và học sinh dường như bắt đầu tập trung vào những xung đột cá nhân hơn là công việc của lớp học.

Đơn giản bởi vì học sinh đã bắt đầu cảm thấy mệt mỏi với những bạn bè xung quanh. Ngay cả khi tôi đã thay đổi sơ đồ chỗ ngồi trong lớp học, lập kế hoạch làm việc nhóm có mục đích hơn, và dạy những bài học tương tác có sự phân hóa, những tranh cãi của học sinh vẫn tiếp tục xảy ra. Những điều kỳ diệu đã kết thúc.

\section{Alex Byland ${ }^{1}$ I Hoàng Giang Quỳnh Anh dịch}

Tôi nhanh chóng nhận ra rằng chúng tôi cần phải tiếp cận lớp học của mình theo nhiêuu cách khác biệt để đảm bảo rằng năm học này sẽ thành công. Trong các kế hoạch, đông nghiệp của tôi và tôi quyết định thay đổi vai trò của một vài học sinh trong bài học sắp tới để theo dõi những biến chuyển trong thói quen của họ và tách họ ra khỏi những xung đột cá nhân - điều có thể tác động đến các hành vi tích cực trong lớp học. Kết quả đã khiến chúng tôi thực sự ngạc nhiên. Mức độ tham gia của học sinh tăng vọt, học sinh tương tác một cách tích cực với những nhóm mới, và hơn tất cả, học sinh làm chủ các bài học. Tôi tự hỏi: "Có phải chúng tôi đã tìm ra chìa khóa để khởi động lại thời kì tốt đẹp trước đó không?"

Trong năm học, học sinh của chúng tôi tiếp tục đạt được những thành công khi chúng tôi thay đổi mục đích làm việc của các nhóm trong từng lớp học. Tôi đã tạo nên một danh sách 5 chiến lược đã thực hiện thành công để bạn cũng có thể loại bó những rào cản trong lớp học của mình và làm việc thông minh hơn, ít khó khăn hơn, nhìn thấy hiệu quả rõ ràng hơn. 


\section{Trao quyền lãnh đạo cho những học sinh có nhữing hành vi thách thức}

Tôi nhận thấy rằng những học sinh có hành vi thách thức là những học sinh có tiềm năng lãnh đạo cao nhất. Những học sinh khác sẽ theo các học sinh này, thậm chí cả khi có những tác động tiêu cực lên mình.

Với vai trò là một nhà giáo dục chuyên biệt, tôi thường đưa học sinh vào các nhóm không giống nhau trong các bài học. Trong kế hoạch của mình, tôi coi quyết định đưa học sinh ra khỏi các nhóm như là một cơ hội để tách một số học sinh có các hành vi thách thức ra khỏi nhau. Trước bài học, tôi phân các vai trò cho các học sinh lãnh đạo, như là hỗ trợ nhóm, người quản lý thời gian và người kiểm tra mục tiêu. Bằng cách ghép các học sinh có tố chất lãnh đạo với những thành viên thường đấu tranh với việc học, chúng tôi quan sát thấy sự tập trung của các nhóm vào mục tiêu bài tập cũng như cải thiện về điểm số.

\section{Nhóm lại céác nhóm họe sinh dụia trên tiêu chuẩn thiếu hụt}

Nếu một nhóm học sinh đã nắm vững một tiêu chuẩn cụ thể, họ có nhiều khả năng sẽ buồn chán và gây rối, đặc biệt là khi bị buộc ngồi học các bài học giống nhau với những học sinh khác. Nhóm giáo viên của tôi đã thành công trong việc ghép các học sinh từ ba lớp trong khóa học thành 7 nhóm dựa trên nguyên tắc thiếu hụt tiêu chuẩn. Có thể xác định các học sinh nắm vững các tiêu chuẩn chỉ trong vòng ba ngày. Để xác định nhóm này, chúng tôi thực hiện đánh giá việc nắm vững các tiêu chuẩn của học sinh qua những đánh giá trước buổi học, những câu hỏi khởi động, và các phiếu đánh giá kết thúc mỗi buổi học theo các dạng câu hỏi nhiều lựa chọn hoặc những câu hỏi có kết thúc mở phù hợp với mục tiêu hoặc tiêu chuẩn bài học.

Bạn có thể băn khoăn làm thế nào để xác định được những học sinh thực sự nắm vững các tiêu chuẩn trong sự trộn lẫn như vậy? Hai gợi ý tiếp theo sau đây có thể giải quyết điều đó. 
Thử thách những học sinh khá bằng các dụ๋ án mơ rộ̂ng

Tôi tự nhận thấy rằng thường sự phân hóa trong các lớp học đều để đáp ứng các nhu cầu học tập của những học sinh phải vật lộn với việc học, điều ây gây thiệt thòi cho những học sinh khá. Bằng cách tập hợp các học sinh ở các lớp khác nhau cùng hoàn thành dự án thực tế, tôi đã có thể đưa ra những thách thức hiệu quả hơn với những nhà lãnh đạo cao cấp này. Trong một tuần đâuu tháng Giêng, tôi dạy một nhóm nhỏ gồm các học sinh có học lực khá và thực hiện các đánh giá không bình đằng. Bằng cách tham gia vào các cuộc thi kinh doanh giả định, các học sinh sẽ học cách hợp tác với các công ty kinh doanh đối thủ để phân tích và phát triển chiến lược sáng tạo và xây dựng giá thành cho các kế hoạch tiếp thị truyền thông. Khi các học sinh chia sẻ sự hứng thú của mình về dự án với các học sinh khác, những học sinh trước đây thờ ơ với việc học sẽ bắt đầu làm việc để có những sản phẩm chất lượng cho các dự án mở rộng sau này.

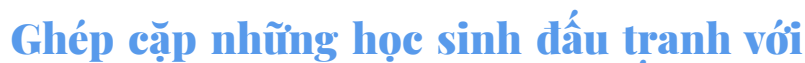
việe họe với mhữing họe simh mắm vững nội dung

Theo kinh nghiệm của tôi, học sinh học tập tốt nhất khi họ có một vai trò tích cực trong việc dẫn dắt bài học. Vì vậy, tôi và các đông nghiệp thường trao quyền lãnh đạo cho các học sinh khá dạy một bài học hoặc kỹ năng cho các bạn cùng lớp. Theo cách tiếp cận này, chúng tôi đề cập tới mô hình hướng dẫn viên du lịch, đó là một cách thức tốt để chuẩn bị cho kì thi hoặc xem lại các bài học. Trong khi từng khách du lịch tiếp cận để nắm vững các tiêu chuẩn, thì các hướng dẫn viên du lịch của họ, những người đã biết nội dung sẽ phát triển kỹ năng giao tiếp và lãnh đạo. Sau khi ghép cặp các học sinh, tôi rà soát lại các vai trò và trách nhiệm cá nhân. Các hướng dẫn viên du lịch phải đảm bảo rằng các khách du lịch của mình đều hiểu các chỉ dẫn, hợp tác với người hướng dẫn để làm sáng tỏ vấn để. Để kiểm tra lại bài học, tôi gộp các kiến thức vào một cuộc thi cạnh tranh với các lớp khác.
Hình thức liên minh xuyên cấp lớp để những họe sinh lớp cao hơn có thể dạy kèm cập lợp thấp hởn

Hầu hết các tiêu chuẩn trong chương trình giảng dạy đều được tăng dần độ khó theo mỗi năm để học sinh có thể xem xét và làm chủ các tài nguyên học tập. Đây là một cơ hội để giáo viên có thể xây dựng mối quan hệ đối tác hai bên cùng có lợi. Ví dụ, năm ngoái các lớp STEM đã dành hai tiết để dạy học sinh lớp của tôi cách thức sử dụng thước đo góc và la bàn để đo lường và xây dựng tam giác một cách độc đáo. Học sinh của tôi được hưởng lợi từ sự giúp đỡ của các cá nhân và những ví dụ từ các trợ giảng cùng trang lứa. Đồng thời, sự hợp tác cũng giúp nâng cao hơn trình độ của học sinh lớp STEM, giúp họ tăng cường khả năng làm chủ kiến thức, tư duy phê phán và kĩ năng giao tiếp.

\section{Hãy lbắt đlầu vởi một kế hoạch}

Hãy thử một lần. Bạn sẽ ngạc nhiên với việc dạy học "không có những rào cản". Trong kế hoạch giảng dạy, hãy thỏa thuận với học sinh một cách thức đánh giá quá trình chung. Sau đó tại các buổi tiếp theo, xác định việc phân chia các nhóm dựa trên kết quả của buổi học trước. Cách tiếp cận này có thể sẽ giúp bạn tiết kiệm khoảng thời gian cuối cùng vì nó thúc đây sự tham gia của học sinh vào mục đích bài học hơn là chú tâm tới nhu câu cá nhân. Ngoài ra, việc kết hợp này cũng giúp học sinh (và cả giáo viên) giảm bớt mệt mỏi thường gặp bởi những lề thói cũ.

Hãy phá bỏ những rào cản trong lớp học của bạn, điêuu ây không chỉ động viên học sinh mà bản thân bạn cũng cảm thấy vui hơn. 


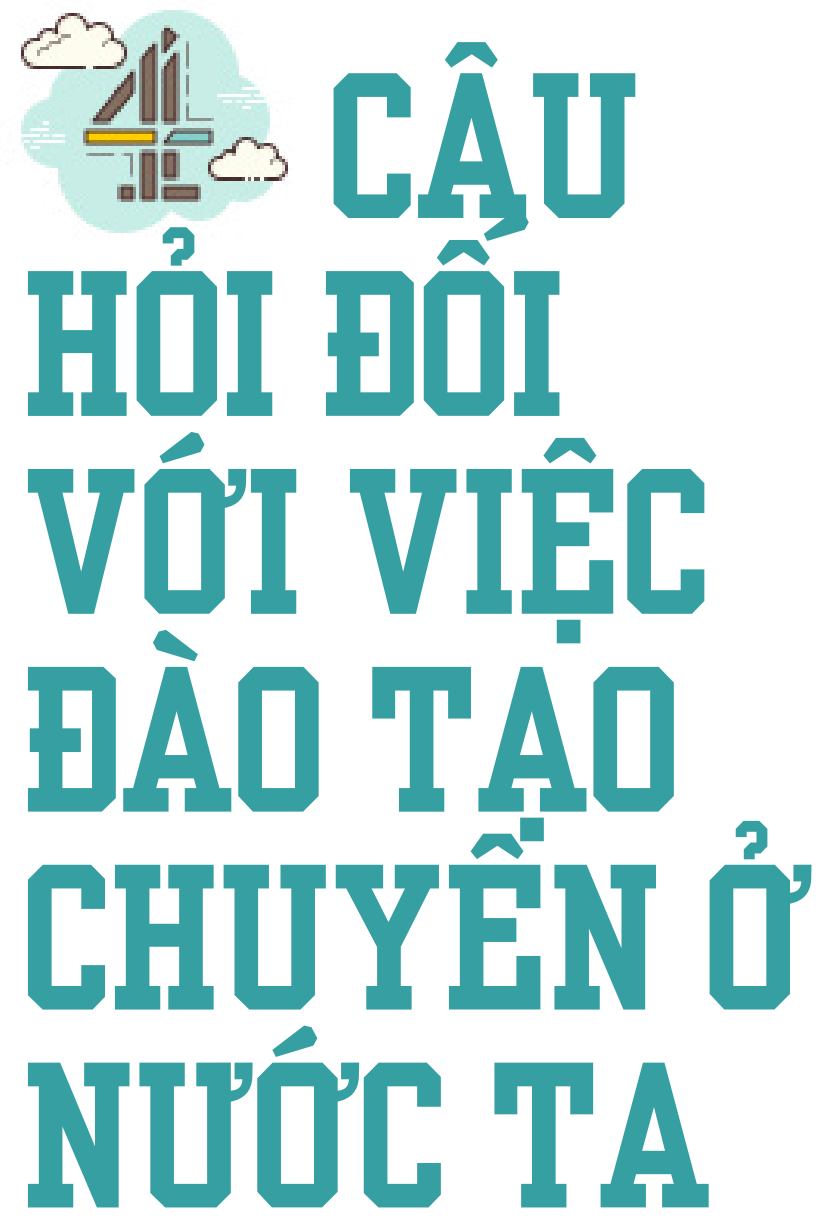

Phạm Hiệp
Đã gần 60 năm kể từ lớp chuyên đầu tiên ra đời tại miền Bắc, hệ thống đào tạo chuyên, bao gồm các trường chuyên (hay năng khiếu) và các kỳ thi học sinh giỏi đã phát triển mạnh mẽ trong khắp cả nước; trải qua nhiều giai đoạn khác nhau nhưng đều giữ mô hình hoạt động tương đối ổn định. Hiện nay, trong bối cảnh mới, liệu hệ thống này có cần những thay đổi để bắt kịp thời đại.

\section{NHIN TỪ THẾ GIỚl: BÀN VỀ KHÁl NIÊM ĐÀO TAO CHUYÊN}

Trên thế giới, có rất nhiều mô hình đào tạo chuyên khác nhau, với những tên gọi không phải lúc nào cũng hoàn toàn giống nhau; hoặc có khi có tên gọi giống nhau, mà lại có nội hàm khác nhau về đào tạo chuyên. Nhưng một cách tổng quát, đào tạo chuyên có 3 tên gọi phổ dụng nhất như sau:

- Specialized education: dịch tiếng Việt là "đào tạo chuyên"

- Gifted education: dịch tiếng Việt là "đào tạo năng khiếu"

- Talented education: dịch tiếng Việt là "đào tạo tài năng"

Trong 3 tên gọi trên, có lẽ tên gọi thứ hai là hợp lý nhất theo cả nghĩa tiếng Anh và tiếng Việt: " gifted education" hay "đào tạo năng khiếu". Nói là "specialized education" hay "đào tạo chuyên" đâu đó sẽ không phản ánh được khả năng vượt trội của học sinh so với các bạn đồng lứa. Còn nói "talented education" hay "đào tạo tài năng" thì thực ra đây không phải là từ phù hợp với lứa tuổi học sinh. ở lứa tuổi học sinh, phẩn lớn các em mới bắt đầu bộc lộ "tiềm năng" (chứ không phải "tài năng"), hay nói cách khác, đó là "năng khiếu". Và nhiệm vụ của hệ thống giáo dục là làm sao giúp nuôi dưỡng, phát triển "năng khiếu" đó trở thành "tài năng" trong tương lai.

Trong phần tiếp theo, thông qua bốn câu hỏi, tác giả sẽ lần lượt đối sánh việc đào tạo chuyên ở nước ta so với các nước khác trên thế giới; đồng thời đưa ra các gợi ý cho các nhà làm giáo dục.

\section{CHÚNG TA CÓ NÊN TIẾP TỤC MÔ HİNH ĐÀO TAOO CHUYÊN HIỆN NAY?}

Trong Luật Giáo dục 2019 cũng như 2005 trước kia, các nhà lập pháp ở nước ta đã dành riêng điều số 62 có tên gọi: "Trường chuyên, trường năng khiếu". Và đây cũng chính là đặc điểm nổi bật nhất về mô hình đào tạo chuyên ở nước ta: học sinh có tiềm năng, năng khiếu được học trong các trường chuyên hoặc trường năng khiếu, tùy theo cách gọi của từng địa phương. Cách tiếp cận này là tương đối giống với một số nước trên thế giới như: Áo, Trung Quốc, Phần Lan, Đức, Hong Kong, Hàn Quốc, Hà Lan hay Ba Lan llưu ý: trong 
các nước này, một số có lớp chuyên thay vì có trường chuyên). Học sinh học tại các trường (lớp) chuyên này sẽ có một chương trình riêng đối với môn chuyên của mình: nặng hơn, khó hơn, yêu cầu cao hơn so với học sinh thông thường.

Mặc dù vậy, mô hình trên không phải là mô hình đào tạo chuyên duy nhất trên thế giới. Trong thực tế, còn có hai mô hình khác:

Mô hình khác thứ nhất, tiếng Anh gọi là “acceleration allowed" (tạm dịch: "mô hình cho phép học nhanh"). Theo đó, học sinh có năng khiếu sẽ được phát hiện trong quá trình học chung với học sinh thường; và khi đủ điều kiện nhất định và có nguyện vọng thì em này sẽ được phép học nhảy cóc, vượt lớp. Đôi khi đọc các bài báo ở phương Tây, ta hay gặp các câu chuyện về các thần đồng, kiểu như 12 tuổi đã hoc xong phổ thông; 14 tuối đã vào đại học; 20 tuổi đã xong tiến sĩ. Đó chính là các học sinh chuyên học theo mô hình "học nhanh" này. Một số nước đang áp dụng mô hình này bao gồm: Áo, Trung Quốc, Canada, Phần Lan, Hà Lan...

Mô hình khác thứ hai, tiếng Anh gọi là: "enrichment" (tạm dịch: "mô hình học tăng cường"). Theo đó, học sinh năng khiếu cũng sẽ được phát hiện trong quá trình học chung với học sinh thường; và sau đó các học sinh này sẽ có cơ hội học thêm trong một lớp/câu lạc bộ riêng để phát triển năng khiếu của mình; bên cạnh việc vẫn học cùng các bạn khác. Một số nước đang áp dụng mô hình này bao gồm Đức, Trung Quốc, Canada, Hà Lan, Ba Lan. Một số trường tư ở Việt Nam cũng đang áp dụng mô hình này, nhưng có thể không triệt để bằng, và cũng ít khi gọi là lớp chuyên.

\section{CHÚNG TA CÓ NÊN TIÊP TUC CÁCH THÚC PHÁT HIÊN NĂNG KHIẾU NHU' HIIÊN NAY?}

Cách thức phát hiện năng khiếu như hiện nay ở nước ta chủ yếu dựa vào thi cử. Thường thì học sinh sẽ trải qua một kỳ thi với các môn cơ bản (toán, ngữ văn) và môn chuyên; sau đó, các em đat điểm cao sẽ được tuyển chọn, em nào trượt rồi thì sẽ rất khó chen ngang để trở thành học sinh chuyên trong các năm sau (trừ khi đợi đến đợt chuyển cấp và thi lại). Tất nhiên là thế giới cũng có nơi áp dụng mô hình này. Nhưng họ cũng có mô hình khác. Ví dụ, tại những nơi áp dụng mô hình "học nhanh" hay "tăng cường" thì việc phát hiện năng khiếu chủ yếu dựa vào điểm số, kết quả trên lớp hoặc quan sát, đánh giá của giáo viên trực tiếp giảng dạy. Một số nơi thậm chí tổ chức cả các cuộc phóng vấn sâu hoặc yêu cầu học sinh phải viết luận để thể hiện mong muốn cá nhân.
CHÚNG TA CẦN NUÔI DU'Õ̃NG NĂNG KHIẾU CỦA HOC SINH NHU' THË NÀ?

Đây là nội dung mà người viết cho rằng chúng ta làm kém nhất hiện nay. Thậm chí, có thể nói, mô hình nuôi dưỡng năng khiếu đối với học sinh sau khi hết bậc phổ thông ở nước ta còn có những điểm phi khoa học, vô lý, thậm chí tiềm ẩn nguy cơ tác động ngược. Cụ thể:

- Công tác định hướng nghề nghiệp, học tập bậc cao ở nước ta hiện chưa được quan tâm đúng mức. Không có chính sách cấp vĩ mô đủ mạnh để giúp học sinh chuyên nói riêng và học sinh nói chung có cơ hội được trải nghiệm, tiếp xúc với các ngành, nghề phù hợp với năng khiếu cá nhân cũng như các trường đại học có ngành đào tạo tương ứng. Các nỗ lực với nội dung này hiện nay chủ yếu vẫn là tự phát và manh mún.

- Chính sách tuyển thẳng cho phép học sinh đạt giải quốc gia lchủ yếu cũng là học sinh trường chuyên) có thể đăng ký nhập học bất kỳ chương trình nào ở bậc đại học. Điều đó có nghĩa là một học sinh đạt giải quốc gia môn Hóa có thể được tuyển thẳng vào làm sinh viên học ngành thương mại ở bậc đại học; hoặc ngược lại, một học sinh khác đạt giải quốc gia môn văn, nếu thích tuyển thẳng vào làm sinh viên ngành kỹ thuật. Đây là điều phi khoa học, và nó dẫn đến việc nhiều học sinh chọn vào trường chuyên, thi học sinh giỏi không phải là để phát huy năng khiếu của minh mà chi để tuyển thẳng đại học. Đây thực sự là một điểu nguy hiểm cho bản thân em học sinh cũng như hệ thống đào tạo chuyên.

CHÚNG TA CÂN ĐÂU TU' CHO ĐÀO TAO CHUYÊN RA SAO?

Các chính sách hiện hành đều nói rõ đào tạo chuyên sẽ được ưu tiên đầu tư so với đào tạo thông thường. Mặc dù vậy, chúng ta cũng không biết mức độ ưu đãi đó, cụ thể là bao nhiêu: tính trung bình một năm nhà nước đầu tư cho một học sinh chuyên thì nhiều hơn một học sinh thường bao nhiêu. Mặt khác, chúng ta cũng thấy rõ là rất nhiều phụ huynh hiện nay cũng sắn sàng đầu tư thêm để cho con mình phát huy hết tiềm năng. Những người quen trong lĩnh vực đào tạo chuyên cũng đều biết, để đạt được thành tích cao trong các kỳ thi học sinh giỏi, nhiều gia đình cũng đã phải đầu tư rất nhiều chi phí cho con em mình. Cân bằng giữa mức đầu tư của hai bên: nhà nước - gia đình rõ ràng là một vấn đề cần tính đến.

Như đã phân tích ở đầu bài, hệ thống chuyên ở nước ta hiện nay đang đứng trước những 
bối cảnh rất mới. Từ ngoài vào thì đó là xu thế toàn cầu hóa, sự tác động của cách mạng công nghiệp 4.0, cuộc chiến thu hút nhân tài giữa các nước. Từ trong ra thì đó là những yêu cầu mới của nền kinh tế - xã hội; sự xuất hiện ngày càng nhiều của hệ thống trường tư chất lượng cao/trường quốc tế, xu hướng gửi con đi du học ngay ở bậc phổ thông, việc ban hành Chương trình giáo dục phổ thông mới và việc có nhiều bộ sách giáo khoa khác nhau.

Trong khi đó, cách làm đào chuyên ở nước ta, xoay quanh 4 vấn đề nêu trên là hầu như không thay đổi lớn trong hàng chục chục năm.

Và có lẽ, đã đến lúc, cách làm này cần có những điều chỉnh nhất định.

- Bài viết đã được đăng trên Báo An Ninh thế giới giữa và cuối tháng, 03/2020. Xin vui lòng xem tại: http://antgct.cand.com.vn/Chuyende/4-cau-hoi-doi-voi-he-thong-truong-chuyen-585745/

- Bài viết có tham khảo từ nghiên cứu Heuser, B. L., Wang, K., \& Shahid, S. (2017). Global Dimensions of Gifted and Talented Education: The Influence of National Perceptions on Policies and Practices. Global Education Review, 4(1), 4-21 và một sốnghiên cứu khác. 


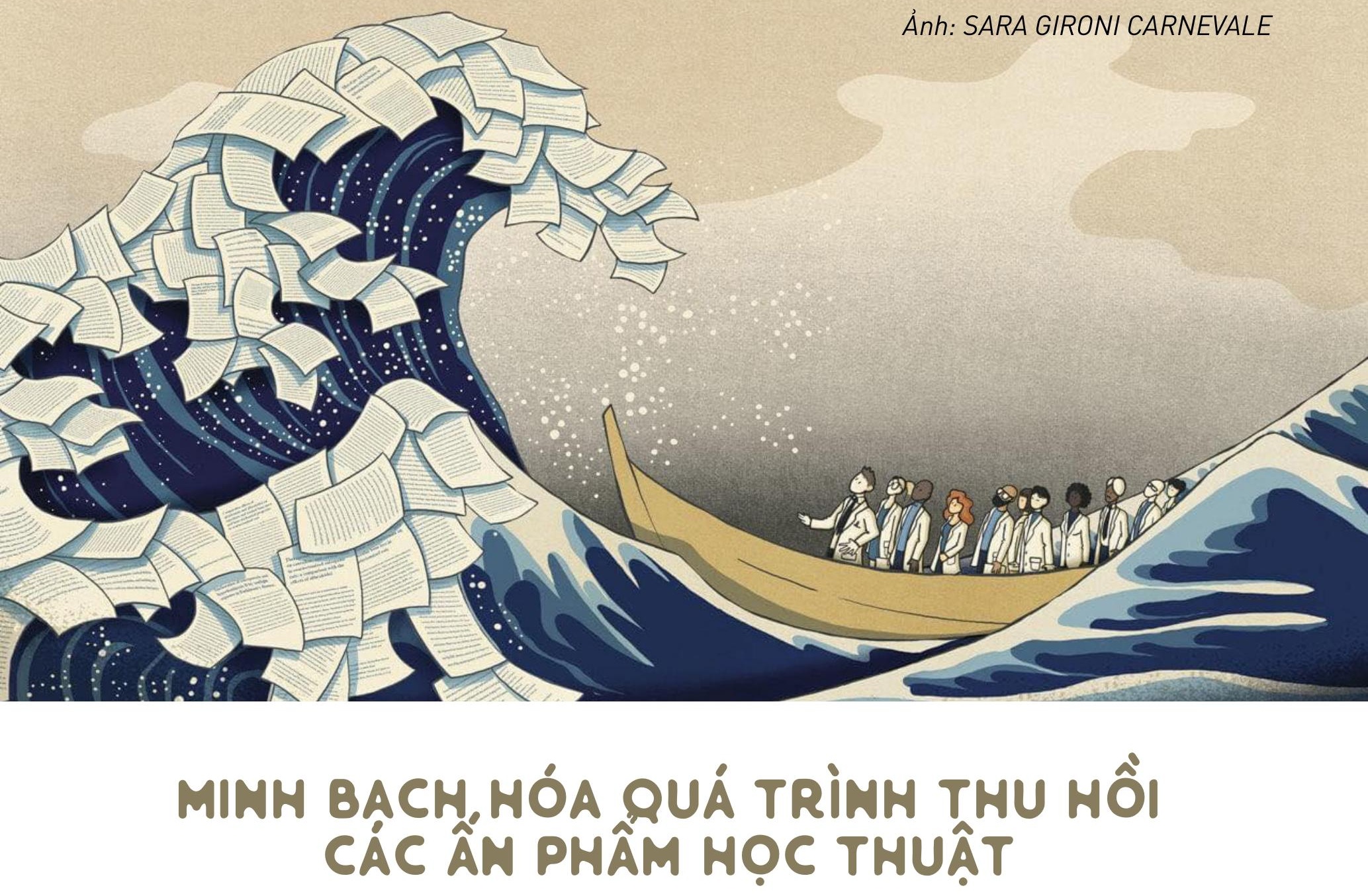

Dương Phú Việt Anh tổng hợp

Vốn là một cơ sở dữ liệu thư mục uy tín hàng đâu của nhà xuất bản Elsevier, Scopus là kho dũ liệu lớn nhất, chỉ mục các bài báo của những nhà nghiên cứu, thủ thư và các tổ chức học thuật trên khắp thế giới. Để đảm bảo tính tin cậy học thuật, mọi ấn phẩm được chỉ mục trên Scopus đều phải trải qua một quá trình bình duyệt trước khi công bố. Ngoài ra, Scopus còn thường xuyên tiến hành những cuộc đánh giá định kỳ về chất lượng của các tạp chí nhằm loại bỏ những tạp chí không đảm bảo. Do đó, danh sách những tạp chí khoa học bị rút khỏi Scopus luôn thường xuyên được cập nhật.

Một nhóm các nhà nghiên cứu đến từ Italy, Thuy Sĩ, Canada và Israel đã thành lập dự án GhoS(t) copus phân tích danh sách các tạp chí bị rút khỏi danh mục Scopus năm 2019 và có được kết quả như sau [1]:
- 93\% các tạp chí ngùng hoạt dộng trên Scopus (294/317) đã chuyển sang mô hìh Truy cập mở (miễn phí).

- Ti lệ dược trich dẫn của các tạp chí đã rút khơi Scopus vẫn tiếp tục tăng cao ltrung binh 64 lẩn trích dẫn).

- Trong số các tạp chí đã rút khơi Scopus, 22\% (72/317) bj dưa vào danh sách den Cabell, trong khi 9\% (29/317) hiện dang ơ trong danh sách dược xem xét dể dưa vào. Chi có 5 tạp chí (2\%) dược đưa vào danh sách trắng cưa Cabell.

- Chi còn 9 trên tổng số 61 tạp chí dược lưu lại trong danh mục các tạp chí truy cập mơ (DOAJ). Nguyên nhân chư yêuu khiến bj loại là do có "hành vi sai trái trong biên tập cưa nhà xuất bán". 


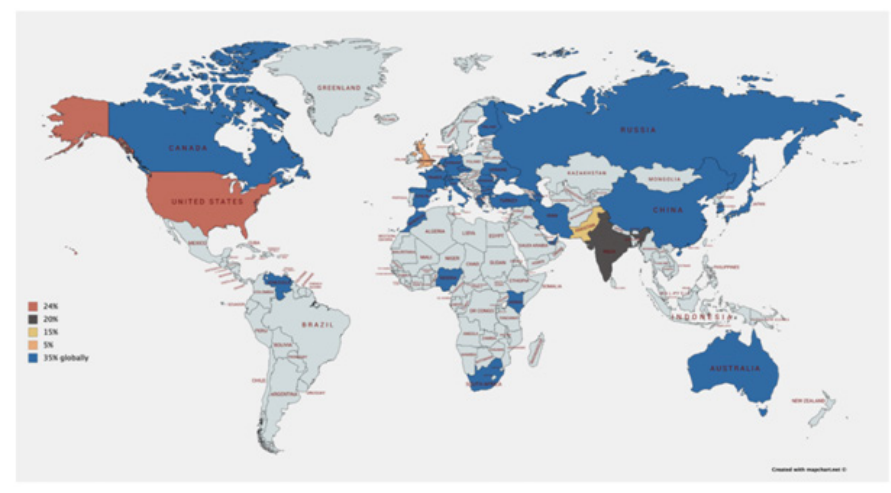

Hình 1. Phân bố các tạp chí bị rút khỏi danh mục Scopus theo quốc gia (Cortegiani et al., 2020)

Có thể thấy rõ, phần lớn các tạp chí ngừng hoạt động trên Scopus có khả năng là tạp chí ngụy tạo, tức là không đáng tin cậy. Nếu người dùng không xem xét kĩ thông tin chi tiết của tạp chí, họ có thể sẽ trích dẫn phải bài của một tạp chí có vấn đề về quy trình xuất bản. Tương tự với các tổ chức và các học viện, việc đánh giá chất lượng nghiên cứu khoa học có thể sẽ bị ảnh hưởng nghiêm trọng.

Ở một phạm vi khác là chuyện rút bài báo ltức một bài nghiên cứu khoa học được công bố, nhưng sau đó bị rút lại). Tuy phạm vi này nhỏ hơn, nhưng vẫn có những hệ quả nhất định mà chúng ta cần cân nhắc. Kể từ năm 2004 tới nay, số lượng các bài báo khoa học bị rút tăng lên đáng kể. Mỗi năm có khoảng 1300-1500 bài và phần lớn trong số đó không công khai những thông tin liên quan [2]. Các nhà xuất bản tạp chí thì vần chưa nhất quán trong cách thông báo với độc giả [3] mặc dù Ủy ban Đạo đức Công bố (COPE) đã có những hướng dẫn cụ thể [4]. Những câu hỏi như: Ai là người đã rút bài báo đó? Bài báo đã mắc lỗi gì?, Liệu rằng chất lượng của các bài báo nghiên cứu có thực sự đảm bảo?,.. thường bị bỏ ngỏ, để lại nhiêu thắc mắc về tính tin cậy và về giá trị của khoa học. Thông tin thiếu rõ ràng như vậy gây ảnh hưởng đến uy tín khoa học và dẫn đến những hiểu nhầm tiêu cực về nghiên cứu khoa học. Theo TS. Vương Quân Hoàng, để hạn chế những hệ quả xấu xí đó, thì quá trình rút bài cần phải được minh bạch hơn bằng cách công khai các thông tin như:

(1) Ai là người đề xuất việc rút bài (ban biên tập tạp chí, tác giả, cơ quan của tác giả, ...)

(2) Lý do rút bài (lỗi kỹ thuật, đạo văn, ngụy tạo dữ liệu, ...)
(3) Có hay không sự đồng thuận giữa ban biên tập và tác giả khi rút bài.

(4) Các đánh giá, nhận định của cộng đồng khoa học về bài viết sau khi rút bài [5].

Một bài báo bị rút đi cũng vẫn có thể để lại những giá trị nhất định cho cộng đồng khoa học. Đó là bài học về sự liêm chính, tự cải thiện mình và củng cố sức mạnh chung của nền khoa học, để những người đi sau tránh đi vào vết xe đổ đã có, ... Ở cả cấp độ tạp chí và cấp độ bài báo, các biện pháp đối phó cần được thực hiện khẩn cấp để đảm bảo tính tin cậy của các số liệu khoa học cho mục đích đánh giá khoa học về xuất bản học thuật.

\section{Tài liệu tham khảo}

[1] Cortegiani A, Ippolito M, Ingoglia G., et al. Inflated citations and metrics of journals discontinued from Scopus for publication concerns: the GhoS(t)copus Project [version 1; peer review: awaiting peer review]. F1000Research $2020,9: 415$

[2] Vuong, Quan Hoang et al., Characteristics of Retracted Articles Based on Retraction Data From Online Sources Through February 2019 (February 20, 2020). Science Editing 2020;7(1): 34-44. Doi: https://doi.org/10.6087/kcse.187

[3] Davis, P. M. (2012). The persistence of error: a study of retracted articles on the Internet and in personal libraries. Journal of the Medical Library Association: JMLA, 100(3), 184.

[4] Committee on Publication Ethics, 2019, Retraction guidelines; https://publicationethics. org/files/retraction\%20guidelines.pdf

[5] Vuong, Q. H. (2020). Reform retractions to make them more transparent. Nature, 582(7811), 149-149. 


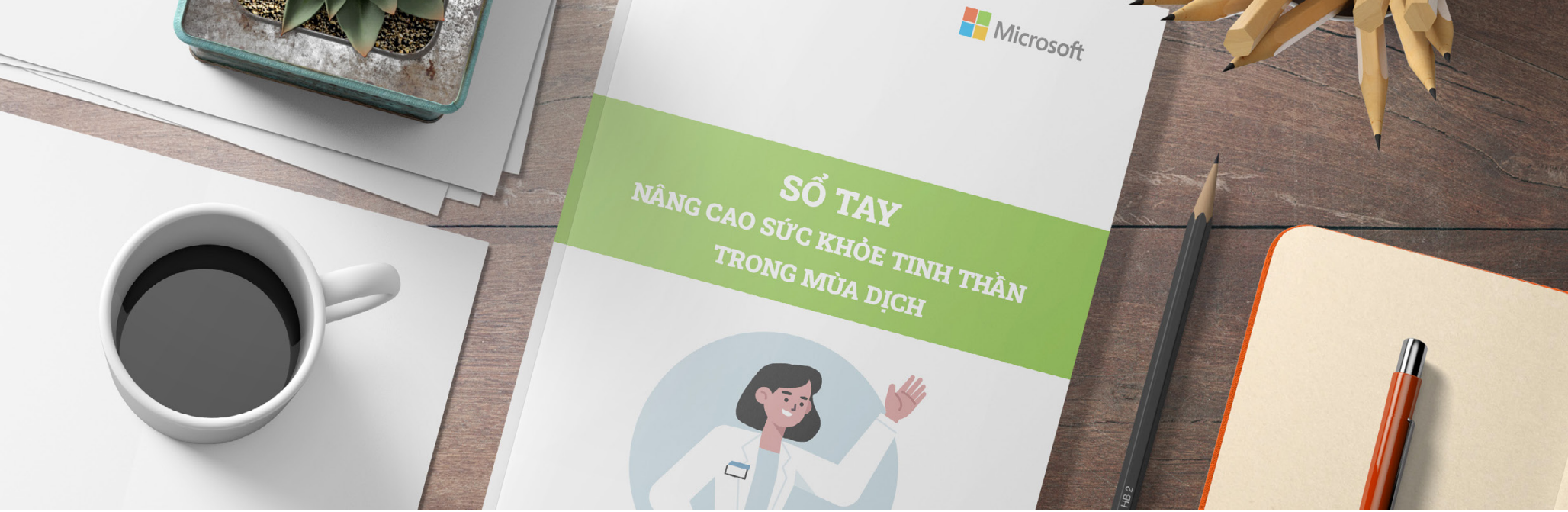

\section{Quý Thầy, Cô thân mến,}

Dịch COVID-19 đang là một trong những vấn đề mang tính toàn cầu, tạo ra bâuu không khí lo ngại ở nhiều nơi và trong nhiều lĩnh vực của đời sống. Nó không chỉ gây ra tổn thất về mặt sức khỏe thể chất mà còn ẩn chứa những tác động không nhỏ đến tinh thần mỗi cá nhân.

Nhằm giảm thiểu các nguy cơ tác động tâm lý có thể xảy đến, Trung tâm Nghiên cứu và Phát triển Giáo dục EdLab Asia đã triển khai chương trình hỗ trợ đặc biệt trong và sau mùa dịch. Cụ thể, chúng tôi triển khai hai hoạt động:

(1) Biên soạn tài liệu "Sổ tay Nâng cao sức khoẻ tinh thần trong mùa dịch" nhằm giúp cho quý thầy cô giáo, quý vị phụ huynh và các bạn học sinh có thể bổ sung thêm các kiến thức thường thức về tâm lý học. Ấn phẩm này không chỉ giúp cho bản thân người đọc nâng cao hiểu biết và cải thiện sức khoẻ tinh thần, mà mỗi người chúng ta cũng đều có thể dựa vào nó để giúp người khác cải thiện sức khoẻ tinh thần, nâng cao hiệu suất làm việc và học tập.

(2) Quy tụ nhóm tình nguyện viên là các chuyên gia tâm lý, sẵn sàng hồ trợ tâm lý cho những người có nhu cầu tại cả ba miền Bắc, Trung, Nam.

Hiện tại, cả sổ tay và danh sách các chuyên gia tình nguyện đều có thể được truy cập tại địa chí: http://edlabasia.org/covid19

Bên cạnh đó, "Sổ tay Nâng cao sức khoẻ tinh thần trong mùa dịch" cũng sẽ được Microsoft Việt Nam hỗ trợ, chuyển tới hơn 22,000 giáo viên trong Cộng đồng giáo viên sáng tạo MIE Việt Nam, cũng như toàn bộ các trường phổ thông đã và đang nhận được sự tài trợ về công nghệ của Microsoft trên khắp cả nước (Hoang et al., 2020).
EdLab hi vọng rằng đây là một ấn phẩm có ích cho cộng đồng, và rất mong nhận được sự ủng hộ của quý Anh, Chị để có thể lan toả được ấn phẩm này.

Xin trân trọng cảm ơn và chúc Anh/Chị cuối tuần tốt lành.

Đội ngũ EdLab Asia

\section{Ghi chú:}

Sổ tay được phát hành theo giấy phép Creative Commons CC BY-NC-ND (Ghi công - Phi thương mại - Không phái sinh) phiên bản 4.0

Bất kỳ ai cũng có thể sao chép, phân phối, trưng bày và trình diễn nhưng phải đúng nguyên văn, nguyên bản tác phẩm, với mục đích phi thương mại, và không được phép có tác phẩm phái sinh từ sổ tay này.

Khi sử dụng, xin vui lòng trích dẫn:

\section{Chuẩn APA:}

Hoang, A. D., Nguyen, Q. N., Chi, N. L., Dao, Q. A., Doan, P. T. T., Dinh, T. T., ... \& Tran, D. H. (2020). Sổ tay Nâng cao sức khoẻ tinh thân trong mùa dịch.

\section{Chuẩn Chicago:}

Hoang, Anh-Duc, Quang Ngoc Nguyen, Nguyen Linh Chi, Quynh Anh Dao, Phuong Thuc Thi Doan, Thu Thi Dinh, Hang Thu Ta, Le Anh Quach, and Duc Hoa Tran. "Sồ tay Nâng cao sức khoẻ tinh thần trong mùa dịch." (2020).

\section{Chuẩn Harvard:}

Hoang, A.D., Nguyen, Q.N., Chi, N.L., Dao, Q.A., Doan, P.T.T., Dinh, T.T., Ta, H.T., Quach, L.A. and Tran, D.H., 2020. Sổ tay Nâng cao sức khoẻ tinh thần trong mùa dịch. 


\section{Ban Biên tập Lộn xộn}

Hoàng Anh Đức

\section{Đặng Thanh Giang}

\section{Lê Thanh Hằng}

Dương Phú Việt Anh | EdLab Asia

Nguyễn Linh Chi | My Baby

Nguyễn Ngọc Diệp | Hogwarts

Phùng Thị Ngọc Lan | Gateway Hải Phòng

Tăng Thị Thuỳ | Dự án Neo Edu

Trần Thị Thu Hương | Dự án Neo Edu

Hoàng Giang Quỳnh Anh | Agilearn

Nguyễn Lê Kim Ngân | THPT Yên Hoà 


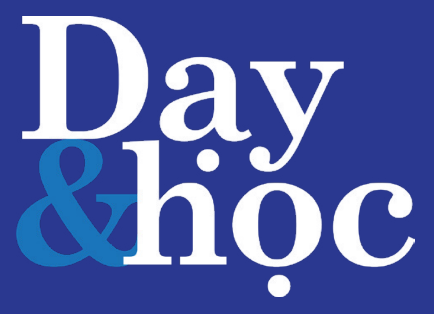

Số 18 | tháng 12 - 2019

Ban Biên tập Lộn xộn

\author{
“Học để Dạy, \\ và Dạy để Học
}

